\title{
EXAMEN DE LAS SENTENCIAS DEL TRIBUNAL DE ESTRASBURGO QUE AFECTAN AL REINO DE ESPAÑA ${ }^{1}$
}

\author{
FRANCISCO JAVIER MATIA PORTILLA \\ Catedrático de Derecho Constitucional \\ Universidad de Valladolid
}

\section{SUMARIO}

I. Intenciones y visión de conjunto. II. Análisis de los derechos procesales. III. Análisis de los derechos materiales. IV. Otras disposiciones del convenio.

\section{INTENCIONES Y VISIÓN DE CONJUNTO}

El presente estudio analizará el centenar y medio largo de Sentencias que el Tribunal Europeo ha dictado en relación con el Reino de España ${ }^{2}$. Se pretende examinar cuál es el balance que puede realizarse sobre el respeto de los derechos humanos en nuestro país.

Antes de entrar en detalles, conviene realizar algunas consideraciones generales. Lo primero que debemos subrayar es el escaso volumen de Sentencias del Tribunal de Estrasburgo que tienen su origen en demandas interpuestas contra España. Si nos fijamos, por ejemplo, en el periodo 1959-2015 (aunque la primera resolución que nos afecta es de 1988), observaremos que nuestro país no figura entre los diez primeros Estados concernidos (que son Turquía, Italia, Federación de Rusia, Rumanía, Ucrania, Polonia, Francia, Grecia, Bulgaria y Reino Unido $^{3}$ ).

1 Este trabajo se realiza en el marco del Proyecto de Investigación DER2016-75993-P, sobre España ante Europa: retos nacionales en materia de derechos humanos (30/12/2016-29/12/2020).

2 Todos los textos se pueden encontrar en la base de datos jurisprudencia del Tribunal Europeo de Derechos Humanos (https://hudoc.echr.coe.int/). El Ministerio de Justicia ofrece versiones en castellano (http://www.mjusticia.gob.es/cs/Satellite/Portal/es/areas-tematicas/area-internacional/tribunal-europeo-derechos).

3 Fuente: CEDH: Aperçu 1959-2017. Cour Européenne des Droits de l'Homme. Francia, 2018, p. 3. Aunque se señala, y es cierto, que hay 157 Sentencias relacionadas en este periodo con España, es oportuno recordar que se refieren a 148 asuntos, puesto que 5 Sentencias (Barberá, Messegué y Jabardo, 1994; Miragal Escolano y otros, 1994; Tendam, 2011 y Sociedad Anónima del Ucieza, 2016) retoman asuntos ya tratados y enjuiciados previamente y que otras tres son dictadas por la Gran Sala y no se separan de lo enjuiciado previamente por la Sección competente (Mangouras, 2010; Del Río Prada, 2013 y Fernández Martínez, 2014). Tampoco nos interesan las SSTEDH Díaz Ruano (1994), Trome (1999) y Manzanas Martín, 2013, que son de archivo. 
Tampoco es excesivo el número de condenas impuestas a España ${ }^{4}$. Si nos fijamos en el mismo periodo, hay 103 Sentencias que nos condenan, al menos, por la vulneración de un derecho humano ${ }^{5}$. Y este número es muy inferior al de otros países de nuestro entorno (193 en Alemania, 728 en Francia, 1819 en Italia), y se aleja aún más de los Estados más veces condenados (Turquía, 2988; Federación Rusa, 2127). Si actualizamos estos datos a abril de 2018, debemos engrosar el listado con tres nuevas condenas (Cuenca Zarnoso, Portu Juanenea y Sarasola Yarzaba y Stern Taulats y Roura Capellera).

De estos datos podemos inferir una primera conclusión, y es que, por lo general, hay una adecuada protección de los derechos humanos en nuestro país. Este es un dato que merece ser subrayado y valorado positivamente, pero no magnificado. Si algún sentido presenta el Estado constitucional es proteger la libertad, y a ese empeño deben servir todos los poderes públicos y, especialmente, los tribunales de justicia.

Ahora bien, si examinamos la intervención del Tribunal de Estrasburgo estrictamente relacionada con España podemos ahondar en nuestro examen incorporando dos criterios de análisis, como son el cronológico y el material.

Desde esta primera perspectiva, conviene subrayar que el número de Sentencias relacionadas con España es relativamente escaso hasta el año 2002 (1 en 1988, 1989, 1993, 2 en 1992, 1995, 1996, 1997 y 1999; 3 en 2000 y 2002; y 4 en 1994 y 1998). A partir de esa fecha se incrementa el número de Sentencias significativamente (excepto en 2008 y 2015 con 3 y 4 Sentencias). Contamos con 5 en 2006, 2007, 2008 y 2014, 6 en 2004, 2017 y 2018 (hasta marzo), 9 en 2003, 10 en 2012 y 2013, 11 en 2010 y 2011, 15 en 2016 y 17 en $2009^{6}$.

Algo más preocupante es el número de Sentencias condenatorias, que también ha sufrido una preocupante evolución. En los primeros años (1988, 1989, 1992, 1993 también en 1996, 1999, 2001 y 2002 - se dicta una única resolución en este sentido), y en otros periodos ninguna $(1995,1997)$. El número de Sentencias condenatorias se eleva a 2 en 2007, 2008 y 2015, 3 en 1994, 1998 y 2000, 4 en 2014 y 2018 (hasta marzo), 5 en 2004, 2006 y 2017, 6 en 2010 y 2013, 8 en 2003 y 2012, 9 en 2011, 11 en 2009 y 12 en 2016.

$\mathrm{Y}$, finalmente, conviene hacer notar que algunas resoluciones condenatorias consideran que España ha lesionado, al tiempo, más de un derecho fundamental Y este fenómeno, aislado hasta el año 2009 (solamente había ocurrido una vez en 1993), se ha producido en una ocasión todos los años entre 2009 y 2012, y también en 2014, 2017 y 2018, con la única salvedad de que ha pasado en 2 en $2012^{7}$. Se aprecia, así, también, una evidente progresión negativa en esta variable.

4 Un análisis específico sobre las condenas impuestas a España, Alcácer Guirao, R. BeladíEz Rojo, M. y SÁnchez Tomás, J.M. (coords.): Conflicto y diálogo con Europa. Las condenas a España del Tribunal Europeo de Derechos Humanos. Civitas. Madrid, 2013. Más recientemente, del autor de estas líneas, «España». En MAtia Portilla, F.J. y Álvarez Rodríguez, I.: Informes nacionales europeos sobre el Tribunal Europeo de Derechos Humanos. Tirant Lo Blanch. Valencia, 2018, pp. 37 ss.

5 CEDH: Aperçu 1959-2017, cit., pp. 8-9.

6 Ninguna Sentencia se dicta en 1990, 1991 y 2005.

7 Aludimos a las Sentencias Ruiz Mateos (1993, derecho al proceso debido por no respetar la igualdad de armas y dilaciones indebidas), Iribarren Pinillos (torturas y tratos inhumanos o degradantes — dimensión procesal— y dilaciones indebidas), Tendam (2010, presunción de inocencia y propiedad privada), Serrano Contreras (2012, inmediación y dilaciones indebidas), B.S. (2012, tratos degradantes — dimensión procesal- y discriminación racial), Del Río Prada (principio de legalidad penal y detención irregular), Varela Geis (2013, derecho ser informado 
A la vista de estos datos se pueden realizar algunas consideraciones. La primera es que existe cada vez una mayor litigiosidad con el Tribunal Europeo de Derechos Humanos. El número de resoluciones y condenas dictadas en el presente siglo, especialmente a partir de 2009, es preocupante por su volumen y porque también se disparan las Sentencias que incluyen condenas por más de un derecho humano (en los años 2012, 2013, 2014, 2017 y lo que llevamos de 2018).

¿Cómo pueden explicarse racionalmente estos datos? A priori debería afirmarse que estamos en presencia de una paradoja. Si, como ya se ha indicado, la protección de los derechos presenta un alto nivel en nuestro país, y además, los operadores jurídicos españoles son sensibles en relación con la jurisprudencia dictada por el Tribunal de Estrasburgo, lo lógico es que los temas sometidos al escrutinio de esa jurisdicción fueran escasos y, por lo general, plantearan asuntos novedosos.

Sin embargo, esta percepción pierde consistencia cuando se examina la jurisprudencia del Tribunal relacionada con España desde una perspectiva material. Vemos, entonces, que las condenas ni siempre han servido para corregir una doctrina cuestionable por parte de nuestros Tribunales ni recaen sobre temas novedosos.

Antes de abordar esta materia, que será examinada en los siguientes epígrafes, resulta conveniente realizar algunas consideraciones generales y alguna acotación a la hora de abordar nuestro estudio.

En relación con la presentación general, debemos señalar que nuestra intención no es abordar un análisis global de la doctrina vertida en relación con el Tribunal de Estrasburgo en relación con todos y cada uno de los derechos humanos recogidos en el Convenio. No solamente porque tal pretensión sería absurda por inabarcable en un trabajo de estas características, sino también porque ya existen estupendos estudios en esta dirección ${ }^{8}$. Sí que puede ser interesante, no obstante, dar algunas pinceladas de los derechos humanos que han debido ser más veces amparados por el Tribunal Europeo de Derechos Humanos, para ver si lo mismo ocurre en nuestro país, y poder valorar las eventuales divergencias que puedan darse entre el plano europeo y el español.

Pues bien, si centramos el análisis en el periodo 1959-2017, se puede constatar que la mayor parte de condenas tienen que ver con la lesión del derecho al proceso debido $(39,68 \%$, destacando las relacionadas con las dilaciones indebidas), al que le siguen las referidas a los derechos a la libertad personal $(12,95 \%)$ y a la propiedad privada $(11,75 \%)$. Las siguientes condenas en importancia se refieren a la interdicción de torturas y tratos inhumanos y degradantes (en su dimensión procesal, $11,11 \%$ ) y el derecho a un recurso efectivo $(8,56 \%)$.

de la acusación y derecho de defensa), Sociedad Anónima del Ucieza (2014, derecho a un tribunal y propiedad privada), N.D. y N.T. (2017, prohibición de expulsiones colectivas y derecho al recurso) y Portu Juanenea y Sarasola (2018, vulneración simultánea de las dimensiones procesal y material de tratos inhumanos o degradantes), respectivamente.

8 Entre la abundante bibliografía destacan Velu, J. \& Ergec, R.: Convention Européenne des Droits de l'Homme. 2. ${ }^{a}$ ed. Bruylant. Bruselas, 2015; Schabas, W.A: The European Convention on Human Rights. Oxford University Press. Oxford, 2015; Burgorgue-Larsen, L.: La Convention européenne des droits de l'homme. 2. a ed. L.G.D.J. París, 2015; Sudre, F.: Les grands arrêts de la Cour Européenne des Droits de l'Homme. 8. ${ }^{a}$ ed. PUF. París, 2017; y, entre nosotros, García Roca, J. (dir): Europe of rights. A compendium of European Convention of Human Rights. Martinus Nijhoff. Leiden, Boston, 2012 y Lasagabaster Herrarte, I. (dir): Comentario al Convenio Europeo de Derechos Humanos. 3. ${ }^{a}$ ed. Civitas. Madrid, 2015.

9 Fuente: CEDH: Aperçu 1959-2017, cit., pp. 5-6. 
Antes de comparar estos datos con los referidos a las condenas impuestas a España conviene recordar que las lesiones de algunos de estos derechos se concentran en determinados Estados. Así, por ejemplo, la Federación de Rusia acumula 932, 936 y 523 condenas relacionadas con los artículos 5,3 y 13. Y algo parecido ocurre con otros Estados (destacadamente Turquía). Por eso, y por otras razones (por ejemplo, sería preciso dividir las condenas impuestas a un Estado entre los años en los que el Convenio le vincula para presentar parámetros homogéneos ${ }^{10}$ ), debemos de dar una relevancia limitada a estas estadísticas generales.

En relación con la acotaciones que se emplearán en este estudio a la hora de examinar la incidencia material de la doctrina del Tribunal de Estrasburgo en España es preciso señalar, antes que nada, que hemos optado por realizar un examen personal de cada una de las más de ciento cincuenta Sentencias y hacerlo desde la perspectiva propia del Derecho Constitucional. Eso supone que en las siguientes páginas abordaremos un examen que no se compadece ni con el que es general cuando se examina la jurisprudencia del Tribunal de Estrasburgo (realizado casi siempre por preceptos del Convenio) ni con las propias cifras aportadas por el Consejo de Europa ${ }^{11}$. Y este último dato merece alguna justificación suplementaria.

No es inhabitual que el Tribunal de Estrasburgo atienda quejas cruzadas de diversos preceptos. Así, por ejemplo, en el asunto Gani se examina la lesión simultánea de los derechos recogidos en los artículos 3, 6.1, 6.2, 6.3.c y 13 del Convenio, que se inadmiten ad limine por no existir ninguna apariencia de lesión y por falta de fundamentación (ap. 51). ¿Cómo computar estas quejas? En este caso hemos decidido no tomarlas en consideración siquiera. En otras ocasiones, hemos optado por readaptar o recolocar algunas quejas formuladas a otros preceptos que nos parecían los equivalentes en nuestro ordenamiento. Así, por ejemplo, la queja contenido en Alony Kate sobre presunción de inocencia, defensa, principio acusatorio y composición irregular de un tribunal la hemos reducido a la del debido proceso (art. 6.1). Especialmente compleja es la valoración que deba darse a la jurisprudencia referida al principio de no discriminación (art. 14) que, de acuerdo con el Convenio, solamente puede ser invocado en relación con un derecho material.

En relación con las inadmisiones, muchas se justifican en que la queja está mal fundada (art. 35.3), aunque también es muy habitual que el Tribunal de Estrasburgo inadmita o desestime un motivo del recurso si considera que, o bien reproduce otra queja ya examinada ${ }^{12}$, o versa sobre los mismos hechos.

Y también existen, como no, las sagas de asuntos que también matizan nuestro análisis. Así, por ejemplo, tras la ilegalización de los partidos que apoyaban la violencia terrorista, se prestó un especial interés a esta cuestión que hoy ya no existe, pero que absorbe la jurisprudencia sobre elecciones libres (P7.3) e influye decisivamente en la de otros derechos (como es el de asociación, 11).

10 Desde esta perspectiva son significativas las condenas impuestas a Rumanía (1202) y Ucrania (1188).

11 En efecto, no se compadece el número de condenas ni la atribución con la que ofrece el Consejo en el mismo Aperçu 1959-2017, cit., p. 8.

12 Esto ocurre en muchos de los asuntos en los que se invoca el derecho a un recurso efectivo (art. 13). Por ejemplo, el Tribunal ha entendido que esta queja retomaba la referida al derecho a un tribunal (asuntos Díaz Ochoa, 2006; Barrenechea Atucha, 2008; Golf de Extremadura, SA, 2009, o Arribas Antón, 2015). En otros casos la remisión se hace a otros artículos del Convenio (2, 3.1, 8.1 y P7.2). 
Por otra parte, también debemos señalar que hemos tomado algunas decisiones pragmáticas a la hora de abordar este trabajo.

En primer lugar, hemos asimilado las inadmisiones y desestimaciones realizadas en las Sentencias por no complejizar más la cuestión.

En segundo lugar, no hemos tenido en cuenta, conscientemente, que en algunos de los asuntos enjuiciados el Tribunal de Estrasburgo había dictado previamente autos de inadmisión parcial ${ }^{13}$. Aunque su examen matizaría, lógicamente, los datos aquí aportados, confiamos en que no se vean alterados en profundidad.

En tercer lugar, debe tomarse en consideración que las categorías dogmáticas manejadas por el Tribunal de Estrasburgo precisan de cierta adaptación a nuestro ordenamiento constitucional. Así, por ejemplo, como es sabido, entiende el Tribunal que cuando no se investiga la existencia de torturas o tratos inhumanos no se está poniendo en cuestión el derecho a la tutela judicial (en particular, el derecho a un tribunal o de acceso a la jurisdicción), sino el mismo derecho material que prohíbe tales prácticas en su dimensión procesal. Nosotros incluiremos estas quejas en las relacionadas con los derechos procesales por entender que ese es el lugar que deben ocupar entre nosotros ${ }^{14}$.

Finalmente, en cuarto lugar, tampoco vamos a computar ni examinar las Sentencias dictadas por la Gran Sala que mantiene el criterio de la Sección (porque computarlas supondría duplicar las condenas).

Una vez concretado el alcance del presente trabajo, estamos en condiciones de entrar en materia. Lo haremos separando el examen de los derechos materiales y de los derechos procesales. Y vamos a comenzar nuestro examen por estos últimos, por la simple razón de que si nuestros cálculos no son incorrectos, son estos los más invocados y los más veces amparados por el Tribunal Europeo de Derechos Humanos.

En efecto, si nos fijamos en los derechos más veces alegados ante el Tribunal Europeo de Derechos Humanos, siempre según nuestros cálculos, serían los derechos a un recurso efectivo (art. 13, 24), a la inmediación en la segunda instancia penal (art. 6.1, 20); a un Tribunal (art. 6.1, 19), a un proceso sin dilaciones indebidas (art. 6.1, 19). Solamente entonces aparece un derecho material (libertad de expresión, art. 10, 18).

13 Así, por ejemplo AATEDH Brualla Gómez (15/04/1996), Casado Coca (02/12/1991), Castells (07/11/1989), Dacosta Silva (16/11/2004), De Diego Nafria (13/03/2000 y 14/12/2000), De la Flor Cabrera (22/11/2011), De la Fuente Ariza (22/05/2006), Díaz Aparicio (12/10/2000), Díaz Ruano (09/12/1992), Drozd (12/12/1989), Edificaciones March Gallego (15/01/1996 y 24/06/1996), Etxeberría Barrena Arza Nafarroako Audeterminazio Bilgunea y Airako y otros (11/12/2007), Fuentes Bobo (01/06/1999), Gabarri Moreno (17/12/2002), García Manibardo (08/12/1998), García Ruiz (02/09/1996 y 24/02/1997), Gea Catalán (30/03/1993), Golf de Extremadura, SA (18/10/2005), Gomes Pires Coelho (04/11/2003), González Doria Durán de Quroga (04/12/2001 y 20/05/2003), Gorraiz Lizarraga y otros (11/02/2014), Herri Batasuna (11/12/2007), Herritarren Zerrenda (11/12/2007), Iribarren Pinillos (31/05/2005), K.A.B. (27/04/2010), Lacarcel Menéndez (25/10/2005), López Ostra (08/07/1992), López Sole y Martín de Vargas (04/12/2001 y 01/04/2003), Martínez Salas y otros (02/07/2002 y 18/11/2003), Moreno Carmona (03/06/2008), Moreno Gómez (29/06/2004), N.D. y N.T. (07/07/2015), Perote Pellón (10/02/2000 y 03/05/2001), Pescador Valero (03/12/2002), Prado Bugallo (06/09/2001 y 16/04/2002), Puig Panella (04/11/2003 y 22/03/2005), Quiles González (14/01/2003 y 27/04/2004), Raf (21/11/2000 y 12/03/2002), Riera Blume y otros (09/03/1999), Rodríguez Valín (08/02/2001), Román Zurdo y otros (11/10/2011), Ruiz Mateos (06/11/1990), Sáez Maeso (19/11/2002 y 20/01/2004), Scott (22/02/1995), Sociedad Anónima del Ucieza (29/05/2012), Soto Sánchez (12/03/2002 y 20/05/2002), Tejedor García (15/05/1995 y 26/02/1996), Trome (13/01/1997), Unión Alimentaria Sanders (11/12/1987), Vaquero Hernández y otros (02/05/2007 y 09/12/2008), Varela Geis (20/09/2011), Vera Fernández-Huidobro (04/05/2004 y 02/05/2007) y Verdú Verdú (14/02/2006).

14 Como acredita la doctrina contenida en la STC 224/2007, de 22 de octubre. 
Evidentemente si hubiéramos optado por aglutinar todas las quejas referidas a distintos aspectos del derecho al proceso público las cifras hubieran sido mucho más altas ${ }^{15}$.

Y a la misma conclusión se llega si nos centramos en el número de lesiones decretadas por el Tribunal Europeo de Derechos Humanos. Los primeros cinco puestos vienen ocupados por derechos procesales: derecho a un proceso público sin dilaciones indebidas (art. 6.1, 16), derecho a un tribunal (art. 6.1, 14), derecho a la inmediación en la segunda instancia penal (art. 6.1, 14), falta de investigación efectiva cuando se denuncia la práctica de torturas o tratos inhumanos o degradantes (art. 3,11) y derecho a un tribunal imparcial (art. 6.1, 7). Empata en esta posición con el derecho material más invocado, que no es otro que la libertad de expresión (art. 10, 7).

Estos datos explican sobradamente que comencemos nuestro estudio por el análisis de los derechos procesales.

\section{ANÁLISIS DE LOS DERECHOS PROCESALES}

\section{II.1. Visión de conjunto}

Antes de centrar nuestra mirada en algunos derechos en particular, puede ser conveniente presentar una gráfica que nos permita realizar una visión de conjunto. Puede ser útil cuantificar la importancia de las quejas presentadas en este tipo de derechos, y su tasa de éxito.

Como ya se ha adelantado, incluimos en este grupo las quejas procesales vinculadas con derechos sustantivos, por entender que en nuestro país encontrarían natural cobijo en el derecho a la tutela judicial efectiva.

Pues bien, si ordenamos de mayor a menor el número de condenas por este tipo de derechos y lo comparamos con el número de veces que el mismo ha sido invocado ante el Tribunal Europeo de Derechos Humanos veremos que el derecho más veces vulnerado es el derecho a un proceso sin dilaciones indebidas (16 condenas y 19 invocaciones), seguido por los derechos a un tribunal (14 de 19) e inmediación en la segunda instancia penal (14 de 20). La dimensión procesal del derecho a la interdicción de tratos inhumanos y degradantes ha sido alegado tantas veces como estimado (11), y a partir de este derecho se separan las condenas de las invocaciones (derechos a un tribunal imparcial, 7 de 11; a obtener una resolución motivada, 4 de 14; principio de legalidad penal, 3 de 7; derechos a un recurso efectivo 2 de 24; al proceso debido, 2 de 9; a ser informado de la acusación, 1 de 4; a la igualdad procesal de armas, 1 de 2; a la ejecución de resoluciones judiciales, 1 de 1. No ha prosperado ninguna de las 2 invocaciones realizadas de los derechos a interrogar a los testigos o en relación con la dimensión procesal del derecho a la vida.

Es muy alto el volumen global de quejas amparadas (78), que supera levemente el $50 \%$ de las quejas examinadas (148). Se acredita así, desde una perspectiva general, la importancia que presenta la tutela de las garantías procesales, puesto que en ella se

15 Hemos separado las quejas relacionadas con el derecho a un tribunal, a un tribunal imparcial, a la igualdad procesal de armas, a la motivación, a la ejecución de la resolución judicial, a la falta de inmediación en la segunda instancia penal y a un proceso público sin dilaciones indebidas, dejando un apartado al derecho al proceso público con otras cuestiones generales o específicas (defensa, derecho a la prueba, etc.). 
concentra el mayor número de condenas (en términos absolutos). Lo mismo ocurre, por cierto, en nuestro propio ordenamiento constitucional. Pese a que la doctrina constitucional del artículo $24 \mathrm{CE}$ ha sido diseñada por el Tribunal desde los años ochenta del pasado siglo, y pese a que la exigencia de que la demanda de amparo presente hoy una especial trascendencia constitucional dificulta mucho que pueda superar el trámite de admisión, el derecho a la tutela judicial efectiva sigue siendo, y con mucho, el más invocado en las demandas admitidas a trámite ${ }^{16}$. Desde esta perspectiva resulta conveniente que el Tribunal Constitucional sea flexible en su actuación para poder seguir ocupándose de garantizar, en toda su plenitud, el derecho a la tutela judicial efectiva. No sólo, y ya sería suficiente, por la importancia del amparo en sí mismo considerado, sino también para poder impedir futuras condenas del Tribunal de Estrasburgo a España.

También destaca, en segundo lugar, la poca efectividad de la queja relacionada con el derecho al recurso efectivo (art. 13). De las 24 invocaciones, solamente 2 han prosperado $^{17}$. Es habitual que el Tribunal de Estrasburgo considere que con esta queja se está reproduciendo otra anteriormente examinada en la Sentencia ${ }^{18}$. Especial interés presentan las Sentencias que diferencian el derecho al recurso del referido a la doble instancia penal, regulado en el artículo P7. $2^{19}$. Estos datos evidencian una indebida utilización y fundamentación de este derecho en las demandas presentadas ante el Tribunal Europeo

16 Como se acredita en la última Memoria del Tribunal Constitucional disponible (2016), p. 252, cuadro 12. En esta tabla, referida a los amparos turnados a la Sala, se da cuenta de que el derecho a la tutela judicial efectiva ha sido invocado en 4.957 ocasiones. Le sigue, muy de lejos, el principio de igualdad (alegado 877 veces). Y no parece que varíen significativamente estos datos en 2017, si atendemos al avance publicado en la página web del Tribunal (http:// www.tribunalconstitucional.es/es/memorias/Estadisticas/Estad\%C3\%ADsticas\%20con\%20gr\%C3\%A1ficos\%20 2017-12\%20v_5\%20Corr_Inadmin_No\%20Comparativas\%20Avance.pdf) (4689 y 795, respectivamente).

17 Son los asuntos A.C. y otros (2014), en relación con los derechos a la vida e interdicción de tratos inhumanos y degradantes, por no conferir carácter suspensivo al decreto de expulsión que ha sido impugnado en sede judicial. Y por hechos muy cercanos en el asunto N.D. y N.T. (2017), en los que se niega al recurso contra una decisión administrativa de denegar el asilo efectos suspensivos en relación con la expulsión. Incluiremos la bibliografía relacionada con este último asunto en la última nota del presente estudio. Ver, en relación con A.C. y otros (2014), San Martín Ontoria, Ana Belén: «Derecho a un recurso efectivo y con efecto de suspensión automática en el ámbito del TEDH». En Pastor Palomar, A.: Temas relevantes de Derecho Internacional Público ante la jurisdicción contencioso-administrativa. Ministerio de Justicia. Madrid, 2016, pp. 87 ss.

18 Muy habitualmente el derecho a un tribunal (asuntos Stone Court Shipping Company, SA, 2003; Díaz Ochoa, 2006; Lacarcel Menéndez, 2006; Barrenechea Atucha, 2008; Golf de Extremadura, SA, 2009 y Arribas Antón, 2015), pero también otros derechos, como son la dimensión procesal de los derechos referidos a la vida (asunto Murillo Espinosa, 2007) y a interdicción de tratos inhumanos o degradantes (asuntos San Argimiro Isasa, 2010 y Beristain Ukar, 2011), el principio de inmediación en la segunda instancia penal (asunto García Hernández, 2010), la ejecución de resoluciones judiciales (García Mateos, 2013), el principio de legalidad penal (Gurguchiani, 2009), derecho a reunirse con su hija (asunto Tapia Gasca y D., 2009), o al respeto del domicilio, en combinación con los arts. 13 y P1.1 CEDH (asunto Aparicio Navarro Reverter y García San Miguel y Orueta, 2017). En los asuntos Etxeberría Barrena Arza Nafarroako Audeterminazio Bilgunea y Airako y otros, y Heritarrren Zerrenda (ambos de 2009), se duelen por el breve plazo conferido para presentar alegaciones en relación con decisiones judiciales relacionadas con la Ley de Partidos (que fue considerado suficiente por el Tribunal de Estrasburgo para defenderse) y en los dos restantes se alega falta de motivación o que no haya ningún recurso contra la denegación del amparo constitucional [asuntos Eusko Abertzale Ekintza - Acción Nacionalista Vasca (EAE-ANV), 2010 y Ferre Gisbert, 2009, respectivamente].

19 Asuntos Bazo González, 2008; Igual Coll, 2009; Valbuena Redondo, 2011 y Pérez Martínez, 2016. Esta disposición solamente vincula a España desde el 1 de diciembre de 2009 (https://www.coe.int/fr/web/conventions/ search-on-treaties/-/conventions/treaty/117/signatures?p_auth=qARm1TH6). Ver GómEZ DE LiAÑo FonsECA Herrero, M.: «La supuesta garantía de la inmediación en la segunda instancia penal española». Revista General de Derecho Europeo, 27, 2012. 
de Derechos Humanos. Y algo parecido podría decirse de las quejas relacionadas con el derecho a obtener una resolución judicial motivada ${ }^{20}$, al proceso debido ${ }^{21}$ y a ser informado de la acusación ${ }^{22}$.

En todo caso, lo relevante es que el grueso de las condenas relacionadas con los derechos procesales se concentra en los primeros cinco derechos referenciados (que alcanzan, en su conjunto, el $79,48 \%$ de las totales), mientras que los restantes ochos derechos procesales acumulan el restante $20,51 \%$ de las condenas. Por eso puede tener sentido examinar, separadamente, esos derechos humanos de forma más detenida.

\section{II.2. El derecho a un proceso sin dilaciones indebidas}

Centrando nuestra mirada en el examen de las condenas impuestas en relación con este derecho humano ${ }^{23}$, se puede realizar un estudio comparado que nos permite concluir, como elemento de análisis, con algunas afirmaciones.

20 Se amparan los casos Ruiz Torija (1994), Hiro Balani (1994), Juez Albizu (2009) e Iglesias Casarrubios y Cantalapiedra Iglesias (2016). No ocurre lo mismo con los asuntos García Ruiz, 1999; Pérez Arias, 2007 y Arribas Antón, 2015, sobre interpretación judicial, y Verdú Verdú (2007) y Saín Casla (2013), sobre motivación realizada por el Tribunal Constitucional. En otros casos se entiende que estas quejas reproducen otras ya examinadas (asuntos Gurguchiani, 2009; Martínez Martínez, 2011, Martínez Martínez y Pino Manzano, 2012).

21 En este apartado constatamos la lesión en los asuntos Barberá, Messegué y Jabardo (1988) y Aparicio Navarro Reverter y García San Miguel y Orueta (2017). En el primero de ellos por las circunstancias en que se produjo el juicio oral de los encausados. En el segundo caso porque no participaron en el proceso judicial que culminó con la orden de demolición de los apartamentos en los que residían, lesionando su derecho de defensa. No se respalda la lesión del derecho al proceso público porque o bien existen defectos procesales que impiden su admisión (no se invocó el derecho a la prueba ante el Tribunal Constitucional en el asunto Gutiérrez Suárez, 2010) o bien reproducen otras quejas (detención irregular, asunto Dactosta Silva, 2006; dimensión procesal del derecho a la vida, asunto Murillo Espinosa, 2007). Finalmente, no se aprecia lesión alguna del derecho en los asuntos Tejedor García (1997), Gorraiz Lizarraga y otros (2004) y Alony Kate (2012). Finalmente, en el reciente asunto López Ribalda y otros (2018) el Tribunal no considera que la utilización de unas grabaciones que han vulnerado la intimidad de los trabajadores afectados en los procedimientos sobre sus despedidos vulnere su derecho de defensa, ya que han podido discutir su autenticidad y contenido $(\S 88)$ y se han presentado otras pruebas testificales ( $\$ 89$ ). Tampoco se aprecia lesión del derecho al proceso debido porque los tribunales confirmen la regularidad de los acuerdos alcanzados entre algunos trabajadores y la empresa para poner fin a su relación contractual, ya que no se ha encontrado prueba alguna que acreditara presiones o coacciones sobre ellos (\$ 94).

Sobre el asunto Barberá ver Castro-Rial Garrone, F.: «Consideraciones a la sentencia del Tribunal Europeo de Derechos Humanos en el asunto «Barberá Messegué» y Jabardo c España». Revista de Instituciones Europeas 1989/3, pp. 789 ss.; Fairén Guillén, V.: «Sentencia del caso «Barberá, Messegué y Jabardo»: Tribunal Europeo de Derechos Humanos (24-1986-122-171-173) de 6 de diciembre de 1988». Revista de Derecho Procesal 1989/2, pp. 295 ss. y Cedeño Hernán, M.: «Las garantías del proceso equitativo en el ámbito penal». En Alcácer Guirao, R. Beladíez Rojo, M. y Sánchez Tomás, J.M. (coords.): Conflicto..., cit., pp. 153 ss.

22 De los cuatro asuntos en los que se invoca este derecho humano (Varela Geis, 2013; Gea Catalán, 1995; Salvador Torres, 1996 y Pérez Martínez, 2016) solamente se ampara, por esta razón, el primero de ellos. Ver, en el plano doctrinal, Tomás Mallén, B. S: «Comentario a la sentencia de 10 de febrero de 1995 del Tribunal Europeo de Derechos Humanos: (Caso Gea Catalán contra España): el derecho a la información del acusado como garantía de la tutela judicial efectiva en el marco del Convenio Europeo de Derechos Humanos». Revista General de Derecho 634635,1997 , pp. 8813 ss.

23 Aludimos a los asuntos Unión Alimentaria Sanders, SA (1989), Ruiz Mateos (1993), Díaz Aparicio (2001), González Doria Durán de Quiroga (2003), López Sola y Martín de Vargas (2003), Soto Sánchez (2003), Quiles González (2004), Alberto Sánchez (2004), Iribarren Pinillos (2009), Bendayan Azcantor y Banalal Bendayan (2009), Moreno Carmona (2009), Ortuño Ortuño (2011), Serrano Contreras (2012), Menéndez García y Álvarez González (2016), Comunidad de Propietarios Pando 20 (2016) y Ruiz-Villar Ruiz (2016). No nos ocuparemos de los asuntos LLavador Carretero (2009), Vaquero Hernández y otros (2010) y Nieto Macero (2013). 
Por una parte, las condenas se han producido a lo largo de los años (desde 1989 hasta 3 en 2016, pasando por otras en los años 1993, 2001, 3 en 2003, 2 en 2004, 3 en 2009, 2 en 2011 y 2 en 2012). Es decir, que estamos ante un problema recurrente en nuestro país. Este dato se evidencia igualmente si se consulta la jurisprudencia reciente del Tribunal Constitucional ${ }^{24}$.

Por otra parte, las lesiones se han producido en todo tipo de procesos e instancias. En efecto hay casos que afectan a procesos civiles ${ }^{25}$, penales -tanto en instrucción ${ }^{26}$ como en el conjunto del proceso ${ }^{27}$-, contencioso-administrativos ${ }^{28}$ y laborales ${ }^{29}$, así como en asuntos complejos ${ }^{30}$. Se han producido dilaciones indebidas en distintas actuaciones judiciales, como son conflictos judiciales de competencia ${ }^{31}$ y ejecución de resoluciones civi$\operatorname{les}^{32}$ y penales ${ }^{33}$. También han sido excesivos los tiempos empleados en procesos desarrollados ante el Tribunal Constitucional (tanto en relación con cuestiones de inconstitucionalidad $^{34}$ como en recursos de amparo $^{35}$ ).

Estamos, pues, ante un problema recurrente y generalizado, que ocasiona otras disfunciones en el modelo judicial español. Merece la pena recordar la atenuación de la condena impuesta cuando se han producido dilaciones indebidas en el proceso penal ${ }^{36}$. Uno de los fines declarados de la Ley 41/2015, de 5 de octubre, de modificación de la Ley de Enjuiciamiento Criminal para la agilización de la justicia penal y el fortalecimiento de las garantías procesales es, precisamente, «evitar dilaciones innecesarias».

Sin embargo, y como ya ha quedado señalado, las dilaciones indebidas se producen en todos los procesos de naturaleza jurisdiccional. Especial interés y discusión generó, entre nosotros, la eventual exigencia de responsabilidad derivada del funcionamiento anormal del funcionamiento del Tribunal Constitucional, que generó sendas resoluciones judiciales muy relevantes y una reforma legislativa ${ }^{37}$.

24 SSTC 63/2016, de 11 de abril; 75/2016, de 25 de abril, 76/2016, de 25 de abril; 77/2016, de 25 de abril; 89/2016, de 9 de mayo; 103/2016, de 6 de junio y 129/2016, de 18 de junio.

25 Asunto Unión Alimentaria Sanders, SA, 1989. Ver GonZÁLEZ GonZÁLEZ, R.: «Comentario a la sentencia del Tribunal Europeo de Derechos Humanos de 7 de julio de 1989 en el asunto Unión Alimentaria Sanders, SA». Revista de la Facultad de Derecho de la Universidad de Granada, 17-20, 1989-1992, pp. 389 ss.

26 Asunto Moreno Carmona (2009).

27 Asuntos González Doria Durán de Quiroga (2003), López Sola y Marín de Vargas (2003), Serrano Contreras (2012) y Menéndez García y Álvarez González (2016). Ver Quispe RemóN, F.: «España y la violación del debido proceso: el caso Serrano Contreras». REDI, 2012/2, pp. 288 ss.

28 Asuntos Alberto Sánchez (2004), Comunidad de Propietarios Pando 20 (2016) y Ruiz-Villar Ruiz (2016).

29 Asunto Quiles González (2004).

30 Proceso penal y contencioso-administrativo en el asunto Iribarren Pinillos (2009).

31 Asunto Alberto Sánchez (2004).

32 Asunto Ortuño Ortuño (2011).

33 Asunto Bendayan Azcantot y Benalal Bendayan (2009).

34 Asunto Ruiz Mateos (1993).

35 Asuntos Díaz Aparicio (2001) y Soto Sánchez (2003). Sobre Sánchez Soto, ver Ortega Carballo, C.: «El derecho a un proceso judicial sin dilaciones». En Alcácer Guirao, R. BeladíEz Rojo, M. y Sánchez Tomás, J.M. (coords.): Conflicto..., cit., pp. 223 ss., Montesinos García, A.: «El incumplimiento del plazo razonable según la Sentencia de 25 de noviembre de 2003 del Tribunal Europeo». Revista Jurídica de la Comunidad Valenciana 9 (2004), pp. 93 ss. y MARTínez Sospedra, M.: «Dilaciones indebidas, justicia constitucional y TEDH». Revista Europea de Derechos Fundamentales, 2, 2003, pp. 115 ss.

36 En el plano doctrinal Magro Servet, V.: «Casuística práctica en la aplicación de la atenuante de dilaciones indebidas como atenuante simple y/o muy cualificada». La ley penal, 124, 2017, entre otros muchos.

37 Sentencias AN de 28 de julio de 2008 y TS de 26 de noviembre de 2009 y, en el plano normativo, el artículo 9 de la Ley 13/2009, de 3 de noviembre, de reforma de la legislación procesal para la implantación de la nueva 
No pretendemos en estas páginas aportar soluciones demiúrgicas para un problema como el descrito, pero sí dejar de manifiesto que estamos ante un reto de primera magnitud, dentro y fuera de nuestras fronteras, como acredita la STJUE Gascogne y Gascogne Sack Deutschland $\mathrm{Gmbh}^{38}$, en la que se reconoce que el propio Tribunal de Luxemburgo ha vulnerado el derecho recogido en el artículo 47 CDFUE al incurrir en dilaciones indebidas.

\section{II.3. El derecho a un tribunal}

Las condenas impuestas a España que se relacionan expresamente con el derecho a un tribunal (art. 6.1) son 14, aunque podrían sumarse a esta categoría las referidas a la dimensión procesal del derecho a la interdicción de torturas y tratos inhumanos o degradantes (art. 3), que son otras 11. Si hemos optado por examinarlas en este trabajo separadamente es por las especificidades que presentan. Hay otros 5 asuntos en los que esta queja no ha sido atendida por el Tribunal de Estrasburgo ${ }^{39}$. Y conviene señalar también que el derecho a un tribunal alcanza igualmente a la jurisdicción a la que se solita la ejecución de una previa resolución judicial [asunto Flores Quiros $(2016)^{40}$ ]

Centrándonos, pues, en esos casos, se aprecia que 5 condenas tienen que ver con la tramitación de recursos de casación ante el Tribunal Supremo ${ }^{41}$, y 3 más se relacionan con amparos constitucionales ${ }^{42}$. Aunque se pueda compartir alguna de estas condenas (especialmente la referida al asunto Ferre Gisbert), lo cierto es que no debería ser cuestionable

Oficina judicial. Un buen examen doctrinal es el ofrecido por Cobreros Mendazona, E.: «El difícil problema de la responsabilidad patrimonial por funcionamiento anormal del Tribunal Constitucional». RVAP, 87-88, 2010.

38 Sentencia de 10 de enero de 2017 (T-577/14, EU:T:2017:1). En el plano doctrinal, Marcos Martín, Teresa: «El reconocimiento de la responsabilidad extracontractual de la Justicia Europea por sus propios incumplimientos: el primer pronunciamiento condenatorio por la concurrencia de dilaciones indebidas». Revista General de Derecho Europeo 44 (2018).

39 Son los asuntos Brualla Gómez (1997), Edificaciones March Gallego, SA (1998), Rodríguez Valín (2001), Cañete de Goñi (2002) y Arribas Antón (2015).

40 Sobre esta cuestión, ver también el asunto García Mateos (2013), en el que la jurisdicción ordinaria no ejecuta una Sentencia del Tribunal Constitucional español, y que hemos incluido, como referencia única, en el apartado derecho a la ejecución de una resolución judicial.

41 En todos estos casos, el Tribunal Supremo admite a trámite, primero, e inadmite, mucho tiempo después, el recurso de casación interpuesto. Dicho lapso temporal, que ya evidencia, en sí mismo, clamorosas dilaciones indebidas, se mueve entre los 3 años [asunto Golf de Extremadura, SA (2008)] y los 7 años [asunto Sáez Maeso (2004)], pasando por 4 [asuntos Salt Hiper S.A. (2007) y Llavador Carretero (2009)] y 5 [asunto Barrenechea Atucha (2008)]. Diferente es la cuestión planteada en el asunto Sociedad Anónima del Ucieza (2014), al que aludiremos en el texto. Ver, sobre el asunto Sáez Maeso, Gutiérrez Gil, A. J.: «El derecho de acceso a los recursos». En Alcácer Guirao, R. BeladíEz Rojo, M. y SÁNCHez Tomás, J.M. (coords.): Conflicto..., cit., pp. 249 ss. y BouAzza ARIÑo, O.: «Recurso de casación contencioso-administrativo común y derecho a la tutela judicial efectiva (estudio de las SSTEDH Sáez Maeso y LLavador Carretero c. España». En García DE EnTERría, E. y Alonso GARcía, R. (coords.): Administración y Justicia: un análisis jurisprudencial. Civitas. Madrid, 2012. Vol. 2, pp. 2735 ss. Por otra parte, no se estima que la inadmisión del recurso de casación haya vulnerado el derecho a un tribunal del recurrente en el asunto Brualla Gómez (1997).

42 En el asunto De la Fuente Ariza (2007) se inadmite un amparo primeramente por ser prematuro, al no haber concluido el proceso penal, y posteriormente por falta de agotamiento (al poder interponer un recurso de súplica contra el auto que rechaza la práctica de determinadas pruebas cuando en el mismo se afirma que contra él no cabe recurso alguno). En el asunto Ferre Gisbert (2009) el Tribunal Constitucional considera que un recurso de amparo es extemporáneo porque el recurrente se sirvió de una vía procesal (juicio declarativo) que había sido indicada en cuatro ocasiones por la jurisdicción ordinaria. Como veremos en el texto, en el asunto Rodríguez Valín (2001) se deniega el amparo solicitado. 
que si un tribunal, que ha admitido un asunto a trámite, constata posteriormente la existencia de una causa de inadmisión (incluso en una Sentencia, en la que se espera en principio un pronunciamiento sobre el fondo del asunto), deba tomarla en consideración y extraer la inevitable consecuencia jurídica de decretar su inadmisión. Es lógico que así sea si se recuerda que el cumplimiento de los requisitos procesales resulta imprescindible para que la actuación procesal pueda ser tramitada.

Esta afirmación podría cuestionarse, sin embargo, en el supuesto de que la inadmisión de un recurso (ya sea de casación, ya sea de amparo) no se motive adecuadamente. Como es sabido, el Tribunal Constitucional ha optado, a partir de la reforma su le Ley de 2007, por limitarse a expresar el precepto al que se anuda la inadmisión, sin explicar por qué concurre en ese concreto caso. Y conviene recordar que el Tribunal Europeo de Derechos Humanos ha avalado tal proceder en el asunto Arribas Antón (2015) ${ }^{43}$. Y esta decisión resulta cuestionable porque en tales casos, en que se pone fin al proceso, debería exigirse una motivación más detallada.

Otros asuntos guardan relación con la forma de presentar los recursos. Y en este punto se han planteado dos cuestiones.

¿Es posible hacer llegar un recurso enviándose al órgano judicial competente a través del correo ordinario? Y en este punto el Tribunal ha mantenido un criterio acertado. Si la remisión se hace con una antelación razonable, que permita suponer que llegará en plazo, debe tramitarse [asunto Pérez de Rada Cavanillas (1998)], pero no resulta admisible tal queja si se entregó en correos el mismo día en que vencía el plazo [asunto Rodríguez Valín (2001)], porque el recurrente (que además era abogado) debía saber que llegaría una vez agotado éste.

¿Puede presentarse un recurso en el Juzgado de Guardia, y no a través de las vías previstas en la legislación procesal? El Tribunal de Estrasburgo considera excesivamente rigorista que en este caso el Tribunal Supremo inadmita el recurso [Asunto Stone Court Shipping Company SA ${ }^{44}$ (2003)].

También ha señalado el Tribunal de Estrasburgo que el plazo para la interposición de un recurso por parte de la persona que, (a) no habiendo sido parte de un proceso [asunto Miragall Escolano y otros, (2000)], se ve afectada por el mismo o que, (b) no teniendo noticia de que había sido demandada, aunque su dirección constara en la documentación facilitada al órgano judicial ${ }^{45}$, comienza a correr desde que tiene noticia de su

43 En relación con la inadmisión de recursos de casación y amparo es preciso citar los Autos recaídos en los asuntos Dosamantes (2012) y Bellid y Bellid (2013) en los que se afirma que «vista la especificidad del papel que cumple el Tribunal Supremo, puede admitirse un formalismo más intenso en el procedimiento seguido ante él» en lo que atañe a la inadmisión de los recursos de casación» y que «puede ser suficiente que una jurisdicción superior [pensando en el Tribunal Constitucional] rechace un recurso refiriéndose únicamente a las disposiciones legales que prevén este procedimiento si las cuestiones planteadas en el recurso no revisten una importancia particular o no presentan una posibilidad suficiente para prosperar», respectivamente. Ver, sobre Arribas Antón, GonzÁLEZ Alonso, A. y Ruiz-RisuEÑo MonTOYA, F.: «El nuevo recurso de amparo constitucional a la luz del Convenio Europeo de Derechos Humanos». REDE, 54, 2015) pp. 155 ss. y HeRnÁNDEZ Ramos, M.: «Incumplimiento de la buena administración de justicia del Tribunal Constitucional en la admisión del recurso de amparo». REDC, 108, 2016, pp. 307 ss.

44 Ver García De Enterría, E.: «La Sentencia del Tribunal Europeo de Derechos Humanos de 28 de octubre de 2003, Stone Court Shipping Company, S.A. c. España y las prácticas judiciales españolas para inadmitir recursos». En RAP, 163, 2004, pp. 169 ss.

45 Asunto Díaz Ochoa (2006). Esta regla no opera, lógicamente, cuando hay constancia de que el afectado ha tenido un conocimiento extraprocesal de la causa [asunto Cañete de Goñi (2002)]. Ver, sobre este 
existencia. $\mathrm{O}$ que no puede exigirse una consignación previa para recurrir a quién ha solicitado el beneficio de justicia gratuita [asunto García Manibardo ${ }^{46}$ (2000)]. O que resulte errado que se afirme, cuando se está discutiendo sobre la propiedad una iglesia medieval, que no queda acreditado que se supera la cuantía exigida para recurrir en casación [asunto Sociedad Anónima del Ucieza (2014)]. O que no se confiera efectos retroactivos a una declaración de incapacidad cuando ésta es palmaria a la vista de las declaraciones judiciales de una persona y de la actuación de otros órganos que ordenaron su ingreso en un hospital psiquiátrico [asunto Lacarcel Menéndez (2006)].

En todos estos casos que se acaban de señalar se considera que la interpretación realizada por los tribunales españoles resulta muy rigorista o desproporcionada. Si estos asuntos se clasifican en este derecho fundamental y no en el apartado del derecho a obtener una resolución judicial motivada ${ }^{47}$ es por el efecto que se anuda a la misma, que es poner fin al recurso y vulnerar así, también, el derecho de acceso a la justicia o, en su caso, al recurso. Pero es oportuno hacer notar que esta jurisprudencia referida a la motivación también se ha referido a la actuación del Tribunal Constitucional, y que, por lo general, ha sido deferente con su actuación ${ }^{48}$.

Finalmente, en otras ocasiones, el Tribunal de Estrasburgo considera que la inadmisión del recurso ha sido motivada por parte del órgano judicial español lo que excluye la lesión aducida por parte del recurrente [asunto Edificaciones March Gallego (1998)].

\section{II.4. Derecho a la inmediación en la segunda instancia penal}

El Tribunal Constitucional ha señalado recientemente que «el respeto a los principios de publicidad, inmediación y contradicción, que forman parte del contenido del derecho a un proceso con todas las garantías (art. 24.2 CE), impone inexorablemente que toda condena articulada sobre pruebas personales se fundamente en una actividad probatoria que el órgano judicial haya examinado directa y personalmente en un debate público, en el que se respete la posibilidad de contradicción». Y es que «resulta contrario a un proceso con todas las garantías que un órgano judicial, conociendo a través de recurso, condene a quien había sido absuelto en la instancia o empeore su situación como

último, Pulido Quecedo, M.: «La doctrina constitucional sobre los emplazamientos en el proceso contencioso-administrativo ante el TEDH». Repertorio Aranzadi del Tribunal Constitucional, 2002/3, pp. 2067 ss.

46 Ver Marín LóPEz, J. J.: «Consignación para apelar en el juicio verbal del automóvil y justicia gratuita: España es condenada por el Tribunal Europeo de Derechos Humanos». Actualidad Jurídica Aranzadi, 444, 2000, pp. 1 ss.

47 Hemos incluido en este apartado los asuntos Ruiz Torija (1994), Hiro Balami (1994), Iglesias Casarrubios y Cantalapiedra Iglesias (2016) y García Ruiz (1999). Mientras que el Tribunal de Estrasburgo considera en los tres primeros casos que el tribunal incurre en una incongruencia omisiva, estima que no lo hace en el cuarto. Tampoco se aprecia la incongruencia extra petita invocada por el recurrente en la resoución dictada por el Tribunal Superior de Justicia del País Vasco en el asunto Arribas Antón (2015). El Tribunal Europeo de Derechos Humanos también considera irrazonable que el órgano judicial afirmara que el recurrente no ha aportado un contrato de compraventas, cuando la pretensión de éste es que lo es el contrato de arras en el caso Juez Albizu (2009). Por otra parte, no vulnera este derecho humano que se realicen distintas interpretaciones judiciales de una misma norma jurídica [asunto Pérez Arias (2007)]. Finalmente, el Tribunal considera en otros asuntos [Gurguchiani (2009), Martínez Martínez (2011), Martínez Martínez y Pino Manzano (2012)] que se retoman las quejas referidas con otros derechos (principio de legalidad penal en el primer caso y protección medioambiental en los dos últimos). Completa esta jurisprudencia la recogida en la nota siguiente.

48 Asuntos Verdú Verdú (2007), Saínz Casla (2013 y Junta Rectora del Ertzainen Nazional Elkartasuna (ER.N.E.) (2015). 
consecuencia de una nueva fijación de los hechos probados que encuentre su origen en la reconsideración de pruebas cuya correcta y adecuada apreciación exija necesariamente que se practiquen en presencia del órgano judicial que las valora - como es el caso de las declaraciones de testigos, peritos y acusados (así, entre otras, SSTC 197/2002, de 28 de octubre, FJ 4, o 1/2010, de 11 de enero, FJ 3)—, sin haber celebrado una vista pública en que se haya desarrollado con todas las garantías dicha actividad probatoria» (STC $37 / 2018 / 6$, de 23 de abril). Esta jurisprudencia tiene su origen en la STC 167/2002 y se ha reiterado en docenas de resoluciones posteriores.

Pese a ello, hay un buen número de quejas ante el Tribunal de Estrasburgo relacionadas con el principio de inmediación en segunda instancia penal (20), que se traducen en numerosas condenas (14).

Las condenas afectan a diversas Audiencias Provinciales ${ }^{49}$ y, en cuatro ocasiones, al Tribunal Supremo ${ }^{50}$. En otros casos, se desestima la queja ${ }^{51}$.

Pues bien, desde esta perspectiva conviene subrayar, en primer lugar, que los datos referidos al Tribunal Supremo son bastante razonables. Debemos recordar que, aunque el recurso de casación tiene carácter extraordinario y se vincula con determinados fines tasados (art. 847 LECrim), en la práctica se ha convertido en un recurso de apelación frente a resoluciones dictadas por tribunales penales inferiores. Esta evidente disfunción pretende ser atajada por la Ley 41/2015, de 5 de octubre, de modificación de la Ley de Enjuiciamiento Criminal para la agilización de la justicia penal y el fortalecimiento de las garantías procesales, que atribuye a los tribunales superiores de justicia la competencia para conocer de los recursos de apelación contra las resoluciones dictadas por las audiencias provinciales y a la Sala de Apelación de la Audiencia Nacional las dictadas por la Sala de lo Penal del mismo órgano judicial, que ya ha entrado en funcionamiento. De esta forma, el recurso de casación vuelve a su dimensión natural.

Por otra parte, la diversidad de Audiencias Provinciales afectadas por esta jurisprudencia impide hablar de que exista un problema sistemático en esta materia, aunque haya obligado a la jurisdicción penal de apelación a modificar seriamente sus tradicionales hábitos. Desde esta perspectiva conviene poner de manifiesto que el Tribunal Constitucional ha contribuido decisivamente con su jurisprudencia y su control en esta materia. Y sigue haciéndolo, como acredita su reciente actuación ${ }^{52}$.

En relación con el análisis cronológico, estamos ante una queja que se ha comenzado a plantear en los últimos diez años, salvo 2014 y 2015. En efecto, este alegato ha sido

49 Barcelona, asuntos Almenara Álvarez (2011) y Saínz Casla (2013); Cáceres, asunto Gómez Olmeda (2016); Granada, asunto Porcel Terribas y otros (2016); León, asunto Marcos Barrios (2010); Málaga, asunto Román Zurdo y otros (2013); Murcia, asunto García Hernández (2010); Sevilla, asunto Nieto Macero (2013); Valencia, asunto Igual Coll (2009), Valladolid, asunto Valbuena Redondo (2011). Sobre el asunto Igual Coll, ver Alcácer Guirao, Rafael: «Las garantías del proceso en la segunda instancia penal». En AlCÁCER GuiraO, R. Beladíez Rojo, M. y SÁnchez Tomás, J.M. (coords.): Conflicto..., cit., pp. 285 ss.

50 Asuntos Lacadena Calero (2011), Serrano Contreras (2012), Vilanova Goterris y Llop García (2012) y Atutxa Mendiola y otros (2017). Sobre el penúltimo asunto citada, ver OTAZuA Zabala, G.: «Desencuentro en la interpretación del derecho a la defensa entre tribunales españoles y TEDH». RVAP, 97, 2013, pp. 259 ss.

51 Casos que afectan a la AP Vizcaya, asunto Bazo González (2008); Valencia, asunto Vilches Coronado y otros (2018) y Zaragoza, asunto Hernández Royo (2016) y, en tres ocasiones, al Tribunal Supremo, asuntos Sardón Alvira (2013), Naranjo Acevedo (2013) y Pérez Martínez (2016).

52 En el año 2017 ha dictado sendas resoluciones en las que recuerda la exigencia de inmediación en el recurso de casación (SSTC 125/2017, de 13 de noviembre y 146/2017, de 14 de diciembre). 
invocado en una ocasión en 2008, 2009, 2017 y 2018 — hasta marzo—; 2 en 2010 y 2012, 3 en 2011,4 en 2016 y 5 en 2013. Y el número de condenas se ha concentrado en 2011 y 2013 con 3 condenas, 2010, 2012 y 2016 con 2 y 2009 y 2017 con una. Debe destacarse, pues, el creciente número de ocasiones en que las quejas son desestimadas (en 2013, 2016 y 2018, especialmente). Parece que en este caso los tribunales sí que están tomando nota de las obligaciones que el respeto del Convenio les impone en su actuación.

Lo relevante es que los tribunales no precisan celebrar una audiencia cuando el fallo condenatorio se justifica en cuestiones jurídicas y no fácticas ${ }^{53}$. Y, claro, obviamente, no hay lesión cuando los encausados deciden no asistir o intervenir en la audiencia ${ }^{54}$.

\section{II.5. Investigación de malos tratos}

Ya señalamos que incluiríamos dentro del análisis de los derechos procesales lo que el Tribunal de Estrasburgo denomina dimensión procesal del derecho referido a la interdicción de tratos inhumanos o degradantes y de la tortura. Consiste en que las denuncias de las presuntas víctimas no han sido investigadas con una mínima diligencia. A nuestro juicio, se está menoscabando, cabalmente, en estos casos, el derecho a la tutela judicial efectiva. Así lo ha confirmado nuestro Tribunal Constitucional ${ }^{55}$.

La mera posibilidad de que se estén cometiendo en nuestro país actos tan execrables debería activar todas las alarmas. Es verdad que de la jurisprudencia del Tribunal no se puede derivar, con naturalidad, que así sea (lo que se condena es la falta de investigación, no su existencia efectiva), pero la mera sospecha debería ser eficazmente despejada (o, en su caso, confirmada) por los tribunales de justicia.

Pues bien, todas las quejas admitidas a trámite por parte del Tribunal Europeo de Derechos Humanos, que son 11, han sido estimadas. Primer dato preocupante. También lo es que las condenas sean permanentes desde $2009^{56}$, porque revela que tenemos un serio problema que merecería la adopción de medidas inmediatas.

Es cierto que muchas de las quejas se han producido en el contexto de la lucha contra el terrorismo ${ }^{57}$ que, afortunadamente, ha sido vencido por el Estado de Derecho. Pero si alguna de estas quejas tuviera fundamento, debería ser ventilada y estimada, y sus responsables castigados con todo el peso de la Ley.

53 Como son la interpretación de preceptos penales [asuntos Sardón Alvira (2013) y Naranjo Acevedo (2013)], o la resolución de problemas jurídicos [¿la comercialización del tabaco en España está sometida a un régimen de monopolio?, asunto Bazo González (2008)].

54 Asuntos Hernández Royo (2016) y Vilches Coronado y otros (2018).

55 STC 224/2007, de 22 de octubre.

56 Previamente, el asunto Martínez Sala y otros (2004). Y a partir de 2009 de forma reiterada en los asuntos Iribarren Pinillos (2009), San Argimiro Isasa (2010), Beristain Ukar (2011), B.S. (2012), Otamendi Egiguren (2012), Etxebarría Caballero (2014), Ataun Rojo (2014), Arratibel Garcíandia (2015), Beortegui Martínez (2016) y Portu Juanenea y Sarasola (2018). Ver, en el plano doctrinal, RodRíGuez MonTAÑés, T.: «De nuevo sobre la prohibición de tortura y el deber de investigación efectiva de las denuncias». REDE 48 (2013), pp. 77 ss. y RoIG Torres, M.: «Revisión del delito de tortura tras la reciente STEDH de 7 de octubre de 2014. El debate sobre la tortura de rescate». Revista de Derecho Penal y Criminología, 11, 2014, pp. 295 ss.

57 Con ETA (asuntos San Argimiro Isasa, Otamendi Egiguren, Etxeberría Caballero y Portu Juanenea y Sarasola Yarzaba) y sus brazos, Segi (asunto Ataun Rojo) y Ekin (asuntos Arratibel Garciandia y Beortegui Martínez), en abundantes casos. También con la kale borroka (asunto Beristain Ukar) y con el independentismo catalán (asunto Martínez Sala y otros). 
Algunas quejas merecen un comentario específico, como es la planteada por B.S. ${ }^{58}$ (2012), en la que una prostituta nigeriana fue maltratada en dos ocasiones, o la de Iribarren Pinillos (2009), que versa sobre una persona que recibió el impacto de un bote de humo lanzado por la policía en una concentración que estuvo a punto de hacerle perder la vida. Y la más reciente, también vinculada a personas presuntamente vinculadas con ETA, en la que uno de los recurrentes sufrió «contusiones y erosiones múltiples, y destacadamente una fractura costal y una contusión pulmonar, confirmándose así una pronóstico muy grave» (asunto Portu Juanenea y Sarasola, 2018). Que esto haya ocurrido estando detenido y nuestra justicia haya sido incapaz de esclarecer la autoría del delito e impartir justicia supone una manifiesta lesión del derecho a la tutela judicial efectiva.

Pero este caso ha implicado también la primera condena por la vulneración material del derecho que prohíbe los malos tratos (art. 3). Los jueces Keller, Pastor Vilanova y Serghides consideran que la condena debería haber sido aún más grave, por la comisión de una tortura.

Resulta evidente, en todo caso, que debemos tomarnos, como país, el asunto en serio. Y que deben extremarse las cautelas que impidan (o, cuando menos, traten de hacerlo) los tratos inhumanos o degradantes, así como las torturas. No solamente por estas resoluciones que hemos comentando, sino también porque así lo viene exigiendo, de forma reiterada y motivada, el Comité Europeo para la prevención de la tortura y de las penas o tratos inhumanos o degradantes ${ }^{59}$.

Aunque no somos expertos en estas lides, hay soluciones fáciles de adoptar que podrían mitigar este problema, como es la utilización de videocámaras en comisarías y centros de detención (incluso, el anuncio de la mera posibilidad de que hayan sido instaladas). Como es sabido, la decisión judicial de supervisar la actuación de algunos agentes ha permitido acreditar (en contadas ocasiones, es de justicia decirlo) la existencia de malos tratos. Y en esos casos la actuación del Estado de Derecho debería ser inexorable, ventilando la responsabilidad criminal de su autor, e impidiendo que esa persona siga formando parte de los Cuerpos y Fuerzas de Seguridad del Estado.

No ocurrió esto en los polémicos indultos que beneficiaron a unos mossos de esquadra condenados, por Sentencia firme, por la comisión de un delito de detención ilegal y otro contra la integridad moral (por golpearlo e insultarlo posteriormente) para evitar, en primer lugar, el cumplimiento de las condenas, y asegurar, después, su reingreso efectivo en el cuerpo policial ${ }^{60}$. Lo más grave es que esta actuación del Gobierno no puede considerarse aislada ${ }^{61}$.

Sin embargo, hay también motivos para la esperanza. El Tribunal Constitucional ha afirmado que «del art. 15 CE se desprende un especial mandato de agotar cuantas posibilidades razonables de indagación resulten útiles para aclarar los hechos» denunciados (STC 36/2017/3, de 27 de febrero, y las allí citadas). «Resulta así posible no proseguir

58 Ver GonZález García, J.V: «Actividad de policía y tratamientos inhumanos o degradantes». En SánCHEz Rodríguez, L.I.: El Derecho internacional en el mundo multipolar del Siglo XXI. Iprolex. Madrid, 2013, pp. 825 ss. y Abril Stoffels, R.M.: «TEDH. Sentencia de 25.07.2012». RDCE, 44, 2013), pp. 309 ss.

59 Pueden consultarse las referencias a los informes de 13 de marzo de 2003, de 10 de julio de 2007, de 25 de marzo de 2011 y de 30 de abril de 2013 en http://www.cpt.coe.int/fr/etats/esp.htm.

60 Perandones Alarcón, M.: «El indulto y la interdicción de la arbitrariedad de los poderes públicos». En La ley penal, 103, 2013, pp. 2 ss.

61 Ver http://www.publico.es/politica/pp-psoe-indultaron-39-policias.html. 
con nuevas diligencias de investigación en aquellos casos en que o bien no persistan sospechas razonables sobre los hechos denunciados o bien incluso persistiendo ya se han agotado los medios razonables y eficaces de investigación» (STC 153/2013/4, de 9 de septiembre). Y la investigación debe realizarse «con mayor rigor cuando el denunciante se encuentra en una situación de aislamiento y de total ausencia de comunicación con el exterior» (STC 130/2016/2, de 18 de julio).

Con esta jurisprudencia, nuestro Alto Tribunal acoge y tutela la dimensión procesal del derecho a la interdicción de tratos inhumanos y degradantes y torturas. Es cierto que tal asunción no asegura que las (presuntas) víctimas vean reparados sus derechos ${ }^{62}$, pero sí se impone un alto estándar en la investigación de conductas que no tienen encaje en un Estado constitucional de Derecho que merezca tal nombre.

\section{II.6. Derecho a un tribunal imparcial}

El derecho a un tribunal imparcial ha sido examinado, en relación con España, en 11 Sentencias, y en dos terceras partes de los casos, aproximadamente, el Tribunal de Estrasburgo ha concluido en que tal derecho había sido lesionado (7).

Desde una perspectiva cronológica, se han resuelto estas quejas de forma dispersa en el tiempo ${ }^{63}$, y afectan a diversos órganos judiciales ${ }^{64}$. Eso sí, la mayor parte de las impugnaciones se refieren al orden jurisdiccional penal ${ }^{65}$.

62 Buena prueba de esta afirmación la encontramos en el ATC 36/2017, de 27 de febrero, en el que se inadmite un nuevo recurso de amparo de quién había sido amparado en la STC 153/2013, de 9 de septiembre. Y es que la actuación del órgano judicial resulta irreprochable en esta ocasión, y este hecho no se ve desvirtuado porque rechace la práctica de sendas pruebas propuestas por el denunciante, que no son pertinentes para el fin buscado.

63 Las condenas por la vulneración de este derecho han sido impuestas en los años 1998 (asunto Castillo Algar), 2002 (asunto Perote Pellón), 2003 (asunto Pescador Valero), 2008 (asunto Gómez de Liaño y Botella), 2010 (asunto Cardona Serrat), 2012 (asunto Alony Kate) y 2015 (asunto Blesa Rodríguez). 2010 es el año que destaca en esta materia, puesto que a la condena impuesta se suma la desestimación de la queja en los asuntos Vera Ferández-Huidobro y Polanco Torres y Movilla Polanco. Se inadmite el motivo en 2012 (asunto Fernández Martínez) y se desestima en 2013 (asunto Román Zurdo y otros).

Sobre el asunto Castillo Algar ver Peiteado Mariscal, P.: «El derecho a un juez imparcial». En Alcácer Guirao, R. Beladíez Rojo, M. y SánChez Tomás, J.M. (coords.): Conflicto..., cit., pp. 187 ss.; Jiménez Villarejo, José: «Análisis de la sentencia del TEDH de 28/10/98 dictada en el caso Castillo Algar». Revista del Poder Judicial, 55, 1999, pp. 489 ss.; RodríGuEz Sol, L.: «La imparcialidad objetiva de los tribunales: antes y después de la sentencia del Tribunal Europeo de Derechos Humanos de 28 de octubre 1998 (caso Castillo Algar vs. España)». Revista del Ministerio Fiscal 7 (2000), pp. 95 ss; MuÑIz Vega, G.: «La sentencia del Tribunal Europeo de Derechos Humanos en el Caso Castillo Algar y la jurisdicción militar». La Ley 1999/2, pp. 1677 ss.; ARIAs Domínguez, A.: «Comentario breve a la Sentencia del Tribunal Europeo de Derechos Humanos, Castillo Algar, de 28 de octubre de 1998». Anuario de la Facultad de Derecho, 17, 1999, pp. 233 ss.; RodríGuez Fernández, R.: La contaminación procesal: el derecho al juez imparcial: (causas de abstención y recusación). Comares, Granada, 1999 y RodríGuez RAMOs L.: «Imparcialidad judicial objetiva, La. Comentario a la STEDH de 28 de octubre de 1998, Caso Castillo Algar contra España». Actualidad Jurídica Aranzadi 376, 1999, p. 1. y sobre el referido a Perote y otros casos, MAGro SERVET, V. «La imparcialidad judicial». La Ley Penal, 7, 2004, pp. 93 ss.

64 Siguiendo el orden de la nota anterior, al Tribunal Militar Central en los dos primeros casos, al Tribunal Superior de Justicia de Castilla-La Mancha, al Tribunal Supremo, a la Audiencia Provincial de Valencia, a la Audiencia Nacional y a la Audiencia Provincial de Santa Cruz de Tenerife en lo que atañe a las condenas. Las restantes causas afectan al Tribunal Supremo, al Tribunal Constitucional (en dos ocasiones) y a la Audiencia Provincial de Málaga.

65 Salvo las referidas a un procedimientos contencioso-administrativo (asunto Pescador Valero, 2003) y a dos recursos de amparo (asuntos Polanco Torres y Movilla Polanco, 2010 y Fernández Martínez, 2012). 
Por otra parte, todas las estimaciones se fundamentan en el quebranto de la imparcialidad objetiva, que «consiste en determinar si, con independencia del comportamiento personal del Juez, existen hechos verificables que permitan cuestionar su imparcialidad ${ }^{66}$. Esto ya es una buena noticia que habla bien de los integrantes del poder judicial de nuestro Estado.

Centrada así la cuestión, interesa saber en qué casos el recurrente puede tener cierto temor a que la actuación de determinados Magistrados no sea imparcial. Esto ocurre, por ejemplo, cuando miembros del tribunal sancionador han formado parte de la Sala que confirma el procesamiento del recurrente ${ }^{67}$, o cuando han acordado su prisión provisional ${ }^{68}$. También se compromete la imparcialidad objetiva del Tribunal cuando forma parte del mismo una persona profesionalmente vinculada con una Universidad que está personada en el proceso ${ }^{69}$. Ninguna de estas afirmaciones admite reproche alguno.

Tampoco suscitan dudas la inadmisión y desestimación de la queja en los asuntos Fernández Martínez (2012) y Polanco Torres y Movilla Polanco, 2010). En el primero de ellos el recurrente no recusó a los Magistrados del Tribunal Constitucional afectados por sus creencias religiosas, por lo que hay falta de agotamiento de la vía judicial previa. En el segundo asunto citado, el Tribunal de Estrasburgo entiende que no se ve comprometida la imparcialidad objetiva del Presidente del Tribunal Constitucional porque, meses después de haber resuelto sobre un amparo, publique un artículo de opinión en un diario que había sido inicialmente demandado por el recurrente en un proceso civil que terminaría dando lugar al citado recurso de amparo.

Presentan cierto interés añadido los asuntos Vera Fernández-Huidobro (2010) y Román Zurdo y otros (2013). En el primero de ellos, tras señalar que la instrucción practicada por el Juzgado Central 5 de Instrucción compromete seriamente la imparcialidad objetiva (dado que su titular había formado parte del Gobierno como el acusado y estaba en contacto con personas implicadas en la investigación), entiende que el nuevo instructor delegado del Tribunal Supremo ha corregido los defectos de esa primera instrucción. En efecto, ha realizado una nueva instrucción, autónoma de la anterior, que no se ve comprometido por los errores cometidos en la primera. En el caso Román Zurdo y otros (2013), el Tribunal Europeo de Derechos Humanos afirma que no se ve comprometida la imparcialidad objetiva porque los acusados hubieran emprendido acciones legales contra algunos magistrados en el contexto de otra investigación previa por presuntas irregularidades urbanísticas adoptadas desde el ayuntamiento de Marbella, que resultaron infructuosas. Interesa subrayar la aseveración de que «que la decisión de una de las partes de emprender acciones legales contra un magistrado para dictar una decisión no implica necesariamente la obligación de este último de abstenerse del caso» (§ 52).

66 STEDH Castillo Algar (1998), § 45.

67 Asuntos Castillo Algar (1998), Perote Pellón (2002) y Gómez de Liaño y Botella (2008). En el asunto Perote Pellón también habían prorrogado la prisión provisional del recurrente, y en el último asunto referenciado habían intervenido en más resoluciones dictadas durante la instrucción de la causa.

68 Asuntos Cardona Serrat (2010) y Alony Kate (2012).

69 Asuntos Pescador Valero (2003) y Blesa Rodríguez (2015), aunque entre ambos hay diferencias relevantes. Mientras que en la primera, el gerente del Campus de Albacete de la Universidad de Castilla-La Mancha cuestiona su despido en vía administrativa, en la segunda la Universidad de La Laguna se querella contra un profesor por un presunto delito de falsificación. 
Con el examen de este derecho cerramos el apartado de los derechos procesales contemplados en las Sentencias del Tribunal de Estrasburgo relacionadas con España. Las restantes lesiones de este tipo de derechos son testimoniales.

Así, de las 13 Sentencias en las se cuestiona el derecho a la motivación de las resoluciones judiciales ${ }^{70}$, solamente se ha condenado a España en los asuntos Ruiz Torija (1994), Hiro Balani ${ }^{71}$ (1994), Iglesias Casarrubios y Cantalapiedra Iglesias ${ }^{72}$ (2016) y Juez Albizu (2009). En los tres primeros el amparo se produce porque los tribunales españoles han incurrido en una incongruencia omisiva. En Juez Albizu (2009) se cuestiona la motivación de la inadmisión de un recurso de apelación (que sería para nosotros derecho de acceso al recurso - Cfr., entre otras muchas, STC 129/2017, de 27 de noviembre-).

El principio de legalidad penal ha sido debatido en 7 Sentencias ${ }^{73}$ del Tribunal de Estrasburgo y amparado en tres ocasiones. En la Sentencia Gabarri Moreno se indica que la exigencia de la seguridad jurídica inherente al principio de legalidad penal exige, cuando menos, una rectificación del quantum de la pena impuesta que no ha tenido lugar» (§ 33) (dado que la concurrencia de la atenuante de perturbación mental debería haber supuesto la rebaja en un grado la condena vinculada con el delito, que es prisión mayor), lo que debería traducirse en una condena entre seis años y un día y ocho años, y no en la impuesta (ocho años y un día).

En el asunto Gurguchiani (2009) se cuestiona si la aplicación del polémico artículo $89 \mathrm{CP}$ (precepto que permite la sustitución, total o parcial, de la condena impuesta a un extranjero irregular por su inmediata expulsión), puede ser aplicada a unos hechos acaecidos antes de su entrada en vigor (cuando en la nueva versión se aplica de forma automática y más severa que antes —antes entre 3 y 10 años, y ahora por diez años-). Es de justicia hacer notar que los Tribunales Supremo y Constitucional han modulado el alcance de este precepto para hacerlo compatible con los derechos fundamentales ${ }^{74}$.

70 Además de las citadas en el texto, son las referidas a los asuntos García Ruiz (1999); Verdú Verdú (2007, en relación con la motivación empleada por el Tribunal Constitucional); Pérez Arias (2007, en la que se explica que dos órganos judiciales puedan realizar distintas lecturas del mismo precepto normativo), Saínz Casla (2013) y Junta Rectora del Ertzainen Nazional Elkartasuna (ER.N.E.) (2015), sobre la motivación de un amparo constitucional) y Arribas Antón (2015), sobre la eventual concurrencia de una incongruencia extra petita que no se aprecia. En algunos casos se reorienta la queja a otros derechos. Así, en Gurguchiani (2009), hacia la falta de inmediación en la segunda instancia penal, en Martínez Martínez (2011), hacia la protección de la vida privada y en Martínez Martínez y Pino Manzano (2012), hacia la protección medioambiental en la vivienda. En el asunto López Ribalda y otros (2018) se inadmite por estar mal formulada.

71 Ver Jimena Quesada, L.: «Comentario a las sentencias de 9 de diciembre de 1994 del TEDH (caso Ruiz Torija y caso Hiro Balani)». Revista General de Derecho, 631, 1997, pp. 3707 ss.

72 Ver González De La TAjadA, I.: «En caso de divorcio hay que escuchar al menor». Revista Aranzadi Doctrinal, $2017 \backslash 2$.

73 Además de las tratadas en el texto, deben incluirse en este apartado los asuntos Bazo González (2008), Lacadena Calero (2011), Vilanova Goterris y Llop García (2012) y Pérez Martínez (2016). En todos ellos el Tribunal considera que la queja está mal fundada porque no se considera competente para corregir, por esta vía, errores de hecho o de Derecho.

74 Ver, por todos, Cano-Palomares, G.: «La expulsión de extranjeros como sustitución de la pena de prisión ante el Tribunal de Estrasburgo». REDF, 15, 2010, pp. 259 ss. (especialmente, pp. 273 ss.) y SÁNCHEZ TomÁs, J.M.: «La irretroactividad desfavorable del sustitutivo penal de expulsión del territorio». En AlCÁCER GuIRAO, R.; Beladíez Rojo, M., Y SÁnchez Tomás, J.M. (coords.): Conflicto..., cit., pp. 385 ss. 
Finalmente, en el asunto Del Río Prada ${ }^{75}$ (2012) se considera que también vulnera el principio de legalidad penal que una nueva forma de computar el cumplimiento efectivo de prisión se aplique de forma retroactiva. La aplicación de esta doctrina implica, como consecuencia, que también se esté produciendo una detención ilegal (artículo 5.1) hasta que se produzca la liberación de la recurrente. Como es sabido, este fallo fue confirmado por la Gran Sala un año más tarde.

El Tribunal Europeo de Derechos Humanos ha condenado en dos ocasiones a España por la lesión de los derechos al recurso (artículo 13) y por el derecho al proceso debido (artículo 6.1). De estos derechos ya nos hemos ocupado en detalle ${ }^{76}$.

Nos resta hacer una sumaria referencia a los derechos a la igualdad de armas procesales ( 1 condena de 2 quejas examinadas ${ }^{77}$ ), derecho a la ejecución de una resolución judicial (en que se estima el único alegato realizado ${ }^{78}$ ) y el derecho a ser informado de la acusación ( 1 vez tutelado y 4 veces invocado ${ }^{79}$ ). Estamos en presencia de condenas singulares, de las que no deben extraerse lecciones generales más allá del concreto caso que enjuician.

Finalmente, ninguna condena trae causa de la vulneración del derecho a interrogar o hacer interrogar a los testigos en el proceso (artículo 6.3.d), invocado en sendas ocasiones. En el asunto Marcos Barrio (2010), porque con este alegato se vuelve a plantear la falta de inmediación en la segunda instancia penal (que ha sido previamente estimada). Y en el asunto Gani (2013), en el que se formaliza un alegato complejo (falta de audiencia pública combinado con el interrogatorio a una víctima de un delito sexual), se desestima la queja porque su abogado no asistió a la entrevista celebrada durante la instrucción

75 Ver, en relación con esta resolución y la dictada por la Gran Sala, Cuerda ArNAU, M. L.: «Cambios jurisprudenciales y retroactividad desfavorable». Revista Penal 31 (2013), Rodríguez HorCajo, D.: «Nulla poena sine lege y retroactividad de cambios jurisprudenciales». Anuario de Derecho Penal y Ciencias Penales 2013/1, pp. 252 ss.; SÁnchez Tomás, J.M. «La doctrina Parot ante el Tribunal Europeo de Derechos Humanos: derechos a la legalidad penal y a la libertad». REDE 50 (2014), pp. 151 ss.; y, destacadamente, HuERTA Tocildo, S.: «La anulación de la doctrina Parot por STEDH de 21 de octubre de 2013». En Mínguez RosiQue, M.; PÉrez Manzano, M. y LascuRAín SÁnCHez, J.A.: La tutela multinivel del principio de legalidad penal. Marcial Pons. Madrid, 2016, pp. 265 ss. y Andrés Sáenz de Santamaría, P.: «Acerca del papel del Tribunal Europeo de Derechos Humanos y de la tentación de desacreditar al mensajero». TRC, 33, 2014, pp. 199 ss.

76 Los 24 asuntos y las dos condenas relacionadas con el derecho al recurso han sido glosados supra, en las notas 17-19; y los casos vinculados con el derecho al proceso público en la nota 21.

77 Se ha amparado a Ruiz Mateos (1993) porque no pudo comparecer, en el marco de una cuestión de inconstitucionalidad, ante el Tribunal Constitucional. Esta doctrina ha sido posteriormente matizada en el asunto Gorraiz Lizarraga y otros (2004), entendiendo que es suficiente que las actuaciones permitan conocer su posición, como garantiza la remisión del expediente judicial completo. Sobre la primera sentencia, ver VIDAL Fueyo, C.: «las garantías del proceso equitativo ante la jurisdicción constitucional». En AlCÁCER Guirao, R. BeladíEz Rojo, M. y SÁNCHEz Tomás, J.M. (coords.): Conflicto..., cit., pp. 131 ss., y sobre la segunda, desde una perspectiva diferente, Fernández Valverde, R.: «La presa de Itoiz o el comienzo de una historia interminable de validaciones legislativas (Sentencia del Tribunal Constitucional STC 73/2000, de 14 de marzo y sentencia del Tribunal Europeo de Derechos Humanos STEDH de 27 de abril de 2004)». En García de Enterría, E. y Alonso García, R. (coords.): Administración..., cit. Vol. 2, pp. 2863 ss.

78 En el asunto García Mateos (2013), en el que la recurrente había visto su derecho a la reducción de horario de trabajo, reconocido a través de una Sentencia del Tribunal Constitucional, impracticable, por lo que inició otra acción resarcitoria que tampoco tuvo éxito.

79 Queja planteada en los asuntos Gea Catalán (1995), Salvador Torres (1996), Pérez Martínez (2016) y Varela Geis (2013). Solamente este último caso, en el que se condena a una persona por justificación del holocausto, cuando había sido acusado por negacionismo (y este delito había sido declarado inconstitucional en la STC 235/2007, de 7 de noviembre), prospera en Estrasburgo. 
de la causa, y porque fue considerada más creíble la versión de la víctima (lógica y suficientemente detallada), a la que se suman otras pruebas indirectas.

Y España tampoco ha sido responsable de no investigar debidamente denuncias que comprometen la vida de personas (dimensión procesal del derecho a la vida, artículo 2). Se desestima este alegato en el asunto Murillo Espinosa (2007), porque el Tribunal entiende que la investigación sobre las circunstancias en las que encontró la muerte el hijo de la recurrente fue satisfactoria.

Concluimos así con el análisis de los derechos procesales que el Tribunal Europeo de Derechos Humanos ha examinado en sus Sentencias hasta el momento. Ahora toca hacer lo propio con los derechos sustantivos.

\section{ANÁLISIS DE LOS DERECHOS MATERIALES}

\section{III.1. Visión de conjunto}

Ya se ha indicado que los derechos procesales son los más invocados ante el Tribunal de Estrasburgo y los que han propiciado un mayor número de condenas a España. Y esta afirmación se puede justificar fácilmente, si aportamos ahora algunos datos en relación con los derechos fundamentales materiales más amparados e invocados ante el Tribunal Europeo de Derechos Humanos.

El derecho más amparado (y alegado) es la libertad de expresión (7 amparos de 18 invocaciones). Le siguen, con 4 estimaciones los derechos a la presunción de inocencia (de 12 veces alegado), propiedad privada (de 9), intimidad (de 7), paz medioambiental (de 6), y derecho de padres e hijos a no verse separados (de 5). En 3 ocasiones, de las 8 ocasiones en que ha sido alegado, el Tribunal Europeo de Derechos Humanos ha considerado vulnerado el derecho no sufrir una detención ilegal. En 2 ocasiones ha estimado desconocido los derechos a no sufrir tratos inhumanos o degradantes y el derecho al secreto de las comunicaciones de las 15 y 4 ocasiones en que fueron alegados ante él. Una sola vez ha amparado los derechos a la duración razonable de la detención y el derecho de ser informado de la acusación, de las cuatro ocasiones en que cada una de ellos fue invocada. Contrasta este dato con que la única vez que se ha sometido a su enjuiciamiento la prohibición de las expulsiones colectivas haya condenado a España. Y, finalmente, no se ha producido ningún amparo sobre otros derechos humanos invocados en diversas ocasiones (libertad de asociación, 7; protección del domicilio y derecho a elecciones libres, 3; libertad ideológica, 2; honor, integridad moral, interdicción de trabajos forzados, libertad condicional y matrimonio, 1).

De estos datos destaca, en primer lugar, que España no ha sido condenado con ninguna lesión de una buena parte de estos derechos (asociación ${ }^{80}$, inviolabilidad del

80 Una parte de los asuntos planteados ante el Tribunal de Estrasburgo tiene que ver con la ilegalización de formaciones políticas que apoyan la violencia terrorista [Son los casos Herri Batasuna y Batasuna (2009), Eusko Abertzale Ekintza - Acción Nacionalista Vasca (EAE-ANV) 1 (2010) y 2 (2013)], que no solamente avala la actuación de los tribunales españoles sino que introduce la posibilidad de incorporar la democracia militante en nuestro país. Ver Pérez Sola, Nicolás: «La necesidad social imperiosa de la disolución de los partidos políticos. A propósito de las Sentencias del TEDH en el asunto Herri Batasuna y Batasuna c. España, Etxeberría y otros c. España y Herritarren Zerrende c. España de 30 de junio de 2009». Revista de Estudios Jurídicos 2009/9, pp. 165 ss. y Rodriguez, Ángel: «Batasuna ante el Tribunal Europeo de Derechos Humanos». RDCE, 35, 2010, pp. 195 ss. 
domicilio $^{81}$, derecho a unas elecciones libres ${ }^{82}$, libertad ideológica ${ }^{83}$, derecho al honor ${ }^{84}$, a la integridad moral ${ }^{85}$, a no realizar trabajos forzados ${ }^{86}$ a que no se imponga una fianza desproporcionada que impida la libertad condicional del preso $^{87}$ y al matrimonio ${ }^{88}$ ).

Las condenas se vinculan, pues, solamente, con algunos de los derechos recogidos en el gráfico, y no puede entenderse que sean muy numerosas ni en su conjunto ni si se examina, con más detalle, cada uno de ellos. Esto es lo que haremos a continuación.

\section{III.2. La libertad de expresión}

El artículo 10 ha sido invocado en 18 ocasiones, de las cuales solamente se han derivado 7 condenas. Encontramos quejas dispersas en los años 1992, 1994, 2000,

Otros casos versan sobre la libertad sindical y sus límites [asuntos Aguilera Jiménez y otros (2009) y Palomo Sánchez y otros (2011)]. En el caso Varela Geis (2013), el Tribunal entiende que el alegato, vinculado con la libertad ideológica, debe ser examinada desde la perspectiva del derecho de defensa. Y finalmente, en el asunto Junta Rectora del Ertzainen Nazional Elkartasuna (ER.N.E.) (2015) el Tribunal de Estrasburgo considera que la restricción del derecho de huelga a sindicatos de fuerzas y cuerpos de seguridad prevista en el Derecho español es razonable y que los Estados disponen de un margen de apreciación en esta materia. Ver, SALAS Porras, M.: «La libertad de asociación sindical y el derecho de huelga». Estudios Financieros. Revista de Trabajo y Seguridad Social, 399, 2016, pp. 205 ss.

81 Dejamos fuera de este apartado la invasión de agentes contaminantes en la morada, que ha sido examinado en una categoría autónoma. En los casos Gorraiz Lizarraga y otros (2004) y Aparicio Navarro Reverter y García San Miguel y Orueta (2017) — donde se invocan al tiempo los artículos 8, 13 y P.1.1— se entiende que estas quejas deben ser examinadas desde la perspectiva del artículo 6.1. Finalmente, en el asunto Tendam (2010) no se aprecia indicio de la lesión invocada.

82 Este derecho ha sido invocado en relación con la ilegalización de los partidos políticos, en los casos Etxeberría Barrena Arza Nafarroako Audeterminazio Bilgunea y Airako y otros (2009), Heritarrren Zerrenda (2009) y Eusko Abertzale Ekintza - Acción Nacionalista Vasca (EAE-ANV) 1 (2010). Nos remitimos a lo indicado en la nota 80.

83 La libertad ideológica fue invocada en los casos Riera Blume y otros (1999) y Manzanas Martín (2012). En el primer caso, «el Tribunal no estima necesario entrar a examinar de forma separada el caso desde la perspectiva del artículo 9» vinculada a su eventual desprogramación sobre su pertenencia a un determinado grupo (considerado presuntamente una secta), ya que se ha centrado en su detención ilegal, pese a que ambas quejas presentan una clara autonomía. Y algo parecido ocurre en el caso Manzanas Martín, en el que el Alto Tribunal no considera oportuno ocuparse de esta queja por haber amparado otra previamente $(14+$ P1.1, en este caso).

84 En el asunto Polanco Torres y Movilla Polanco (2010) se recuerda la protección preferente que merece la libertad de información cuando con ella se pretende ofrecer noticias que presentan un interés general ( $\$ 53$ ).

85 Es evidente que la invocación del artículo 8 con ocasión «del carácter desproporcionado de la reacción de los agentes de policía que provocó en él graves lesiones» (§ 35 ) debe ser examinada desde la perspectiva del artículo 3 y que la misma no aporta nada nuevo ( $(60)$.

86 No puede considerarse bien fundamentada la queja de que tener que trabajar mucho para poder pagar la pensión de alimentos judicialmente decretada constituye un trabajo forzado planteada en el asunto Igual Coll (2009), ya que «no hace ninguna referencia, directa o indirecta, sobre la forma en la que el recurrente debe obtener los fondos para pagar la pensión de alimentos» (§ 47).

87 Es el asunto Mangouras (2009), confirmado un año más tarde por la Gran Sala (aunque con un voto discrepante suscrito por 7 Jueces) se cuestiona si la fianza impuesta al capitán del Prestige (tres millones de euros) resulta desproporcionada al. La Gran Sala considera que «los tribunales internados han tomado suficientemente en consideración la situación personal del recurrente, especialmente de su estatuto de empleado del armador, de sus vínculos profesionales con las personas llamadas a prestar las fianzas, de su nacionalidad y de su domicilio así que de la ausencia de arraigo en España y de su edad cuando han fijado el montante de la fianza impugnada» (§ 92). Ver Verdú BAeZA, J.: «Las Sentencias ambientalistas del TEDH». RDCE, 39, 2011, pp. 503 ss.

$88 \mathrm{Y}$ es que no resulta preciso conferir a las uniones realizadas por el rito gitano los efectos pretendidos en la demanda interpuesta en el asunto Muñoz Díaz (2009). 
2002 y 2018 (hasta marzo). En otros años se presentan 2 alegatos en esta materia (2010, 2011 y 2013), que llegan a ser 3 en 2016 y 4 en 2009. Y las condenas son también dispersas en el tiempo (1 en 1992, 2000, 2010, 2011 y 2018, y 2 en 2016). Puede concluirse, en relación con las quejas, que ha habido una importante bolsa en 2009 y 2010 (vinculada, como enseguida se indicará, con la ilegalización de partidos políticos). Y también que 3 de las 7 condenas se han impuesto en los últimos 3 años, lo que resulta preocupante.

Una de ellas, la recaída en el asunto Stern Taulats y Roura Capellera (2018) era prácticamente inevitable. En efecto, como se recordará, los recurrentes habían sido condenados por quemar retratos del Rey boca abajo en una concentración. Con independencia de la consideración moral y psicológica que tal actuación, en su caso, merezca, resulta evidente que la misma no debe ser sancionada penalmente. Especialmente cuando el Tribunal de Estrasburgo ha amparado previamente a un político que ha llamado al Rey Juan Carlos I «jefe de los torturadores» [asunto Otegi Mondragón ${ }^{89}$ (2011)]. Si esta aseveración, manifiestamente injuriosa, había sido protegida por el Tribunal Europeo de Derechos Humanos, era previsible que lo mismo ocurriera con la ahora enjuiciada, sin que pudiera sostenerse, de forma convincente, en contra de lo indicado en la STC 177/2015, de 22 de julio, que estábamos en presencia de discurso del odio $(\S 40)$.

Otra serie de asuntos transcurren en el ámbito laboral. En el asunto Fuentes Bobo ${ }^{90}$ (2000) el Tribunal de Estrasburgo ampara a las declaraciones realizadas por el recurrente sobre los directivos de la TVE en la que prestaba sus servicios. Hay dos factores que pueden explicar el amparo:

a) la referencia a una televisión pública, cuya gestión es una asunto de interés general, y

b) la aplicación de una sanción desproporcionada (en este caso la máxima) (§§ 48 y 50). No corre la misma suerte De Diego Nafría ${ }^{91}$ (2002), trabajador del Banco de España que realizó ataques personales gratuitos, y por escrito.

En varios casos impugnan este derecho, sin éxito, representantes sindicales que han vertido en sus boletines escritos contenidos que pueden ser considerados ofensivos hacia concretos cargos de la empresa, como son el jefe de personal por haber depuesto éste previamente en un proceso judicial previo [en Aguilera Jiménez y otros (2009) y en Palomo Sánchez y otros (2009)].

89 Ver Gómez Corona, E.: «El prestigio de las instituciones como límite a la libertad de expresión de los ciudadanos». REDA 151 (2011), pp. 727 ss.; RodríGUEZ MONTAÑÉs, T.: «El derecho a la libertad de expresión en el ámbito de discurso político extremo». En AlCÁcer Guirao, R. y otros (coords.): Conflicto..., cit., pp. 613 ss. y Soto García, M.: «TEDH, Sentencia de 15.03.2011». RDCE, 42, 2012, pp. 575 ss.

90 Ver Pulido Quecedo, M.: «Libertad de expresión y Tribunal Europeo de Derechos Humanos». Repertorio Aranzadi del Tribunal Constitucional, 2000/1, pp. 1745 ss.; Torres Pérez, A., «Fuentes Bobo y la infra-ejecución de las sentencias del Tribunal Europeo de Derechos Humanos en España». REDE 21 (2007), pp. 145 ss. y DuRÁN Alba, J.F.: «Alcance de la libertad de expresión en el ámbito laboral». En Alcácer Guirao, R.; BeladíEz Rojo, M. y SÁnChez Tomás, J.M. (coords.): Conflicto..., cit., pp. 587 ss. 3147 ss

91 Ver Álvarez Alonso, D.: «Libertad de expresión y despido disciplinario». Aranzadi Social, 2002/1, pp. 
En el asunto Castells ${ }^{92}$ (1992) se ampara a un senador separatista que había escrito un artículo en el que afirmaba que el Gobierno español estaba detrás de grupos fascistas que cometían atentados en el País Vasco. El Tribunal de Estrasburgo subraya el interés social de la denuncia realizada y cuestiona que se denegara la prueba solicitada por el acusado que pretendía acreditar la veracidad de lo publicado.

En el plano de la prensa, se ha amparado a diversos periodistas como Gutiérrez Suárez (2010) y Jiménez Losantos ${ }^{93}$ (2016). El Tribunal considera que la condena civil impuesta al primero de ellos por la publicación de la noticia «Una empresa familiar de Hassan II implicada en el narcotráfico» no resulta necesaria en una sociedad democrática. Y estima que la condena penal impuesta al segundo periodista por un delito continuado de injurias graves y públicas en relación con un ex alcalde de Madrid sobre un asunto de interés general produce un efecto disuasorio sobre los profesionales de la comunicación.

El Tribunal Europeo de Derechos Humanos ha amparado finalmente a un Letrado, Rodríguez Ravelo (2016), que en un escrito de demanda cuestionaba duramente la actuación de un órgano judicial (que ha decidido «falsear la realidad, teniendo por único objetivo dar una apariencia de legalidad a lo que no es más que una tentativa ilegítima de»..., «no ha dudado en mentir», «lejos de contentarse con la interminable sucesión de infracciones cometidas en el procedimiento, el juez [....] Ha decidido cometer una más»). El demandante fue condenado como responsable de un delito de calumnias contra el juez a una multa diaria de 30 euros durante nueve meses (y en caso de 2 días de impago, un día de privación de libertad). Pues bien, una eventual pena de prisión para un abogado presenta un efecto disuasorio para él y para la profesión en su conjunto. Además, las expresiones vertidas se han utilizado en defensa de su cliente, y con un conocimiento limitado al Juzgado al que se dirigen y a las partes procesales. Concluye el Tribunal que una condena de naturaleza penal que conlleva una eventual privación de libertad resulta desproporcionada en este caso. No lo es, sin embargo, que la publicidad de los letrados se vea sometida a ciertas restricciones [asunto Casado Coca ${ }^{94}$ (1994)].

El Tribunal ha desestimado las quejas referidas a la libertad de expresión de aquéllas formaciones políticas (en sentido amplio) que habían sido ilegalizadas por apoyar la violencia terrorista ${ }^{95}$.

Finalmente, no examina el alegato en profundidad en los asuntos Varela Geis (2013) y Cano Moya (2016). En el primero de ellos, referido al librero acusado de negacionismo y condenado por justificar el holocausto, entiende el tribunal que los alegatos de los

92 Ver Teso Gamella, P.: «La sentencia del TC de 16 de diciembre de 1991 — caso Bultó-, y su proyección sobre la tercera condena al estado español por el TEDH, sentencia de 23 de Abril de 1992, caso Castells». Actualidad Administrativa 1992/39, pp. 467 ss. y URÍAs MARTínez, J.: «La libertad de crítica política veraz». AlCÁCER GuIRAO, R.; Beladíez Rojo, M. y Sánchez Tomás, J.M. (coords.): Conflicto..., cit., pp. 557 ss.

93 Ver Climent Gallart, J.A.: «Advocacy journalism y el derecho al honor». Revista Boliviana de Derecho, 23,2017 , pp. 408 ss.

94 Ver Jimena Quesada, L.: «La libertad de expresión y los abogados a la luz del Convenio Europeo de Derechos Humanos». Revista General de Derecho, 600, 1994, pp. 9469 ss.

95 En casi todos estos casos se entiende que esta queja retoma otra desestimada previamente. En los asuntos Herri Batasuna y Batasuna (2009) y Eusko Abertzale Ekintza - Acción Nacionalista Vasca (EAE-ANV) 2 (2013) se vincula con el derecho de asociación y en los asuntos Etxeberría Barrena Arza Nafarroako Audeterminazio Bilgunea y Airako y otros (2009) y Heritarrren Zerrenda (2009) con el derecho a unas elecciones libres (P1.3). En el asunto Eusko Abertzale Ekintza - Acción Nacionalista Vasca (EAE-ANV) 1 (2010) se invoca junto al artículo 11 y el Tribunal descarta la queja atendiendo al margen de apreciación nacional existente en esta materia. 
artículos 9 y 10 reproducen la queja del principio acusatorio, por lo que no procede entrar en este análisis. Y en el segundo caso, el Tribunal no aprecia ninguna apariencia de lesión en la libertad de expresión (ni de la presunción de inocencia) de un recluso porque se le haya incoado un expediente disciplinario, considerando que la queja está mal formulada.

\section{III.3. La presunción de inocencia}

De las 12 veces que se alega el derecho a la presunción de inocencia en las Sentencias del Tribunal Europeo de Derechos Humanos, se han producido 4 estimaciones. Tres de ellas por parecidas razones. En los asuntos Puig Panella ${ }^{96}$ (2006), Tendam (2010) y Vlieeland Boody y Marcelo Lanni (2016) se cuestiona la vía prevista en el artículo 294.1 LOPJ para conseguir una indemnización ante privaciones de libertad sufridas ${ }^{97}$.

En Puig Panella el recurrente fue condenado penalmente, y posteriormente amparado por el Tribunal Constitucional por haberse vulnerado su derecho a la presunción de inocencia. El Ministerio de Justicia y los tribunales denegaran la reclamación cursada por el recurrente en aplicación del citado precepto legal. El Tribunal de Estrasburgo recuerda que «ni el artículo 6.2 ni ninguna otra cláusula del Convenio confiere al acusado un derecho al reembolso de sus gastos o un derecho de reparación por una detención provisional regular en caso de que se abandonen las actuaciones procesales dirigidas contra él ( $\$ 52$ ). Ahora bien, observa también que la decisión del Ministerio de Justicia de denegar la indemnización, al amparo del artículo 294 LOPJ, «en razón de la culpabilidad supuesta (o de la ausencia total en cuanto a su inocencia)» deja planear una duda sobre la inocencia del recurrente $(\S 55)$. Considera el Tribunal que resulta excesivamente severo aplicar un precepto previsto para un caso distinto (prisión provisional) (\$ 56) y que el razonamiento seguido en las resoluciones cuestionadas cuestiona su inocencia (que puede ser determinada tanto por el sobreseimiento de las actuaciones como por una resolución de fondo) ( $\$ 57$ ).

En Temdan (2010) el recurrente es absuelto en apelación y reclama por la prisión sufrida, que le es denegada porque su absolución trae causa de la «falta de pruebas de cargo suficientes y no por la inexistencia objetiva u subjetiva del delito» (§ 39). El Tribunal considera que este razonamiento del Ministerio de Justicia, confirmado judicialmente ( $\$ 40)$, desconoce la previa absolución del acusado, «cuyo fallo debe ser respetado por toda autoridad judicial, con independencia de los motivos utilizados por el juez penal» (\$ 39).

Finalmente, en Vlieeland Boody y Marcelo Lanni (2016), «el primer recurrente ha sido absuelto en primera instancia y el segundo se ha beneficiado de un sobreseimiento provisional del Juzgado de Instrucción previo a la apertura del juicio oral» (§ 41). El Ministerio de Justicia deniega las indemnizaciones solicitadas por la prisión provisional

96 Ver Arroyo Jiménez, L.: «La presunción de inocencia y la responsabilidad patrimonial del Estado por prisión provisional». En AlCÁcer Guirao, R.; Beladítz Rojo, M. y SÁnCHEz Tomás, J.M. (coords.): Conflicto..., cit., pp. 313 ss. y, con carácter general, RodríGUEz-Piñero y Bravo-Ferrer, M.: «Sobre la indemnización por prisión preventiva injustificada». La Ley, 8990, 2017.

97 Que dispone que «Tendrán derecho a indemnización quienes, después de haber sufrido prisión preventiva, sean absueltos por inexistencia del hecho imputado o por esta misma causa haya sido dictado auto de sobreseimiento libre, siempre que se le hayan irrogado perjuicios». 
sufrida por ambos recurrentes porque la absolución del primero de ellos se produce por falta de pruebas (no porque haya quedado acreditada su inocencia) ( $\$ 42$ ) y porque el sobreseimiento que afecta al segundo es provisional y no libre ( $\$ 43)$ —aunque la propia Audiencia Nacional recuerda que el sobreseimiento acordado por inexistencia de indicios racionales en cuanto a la responsabilidad del investigado puede asimilarse a un sobreseimiento libre- ( $\$ 43$ ). Pues bien, dado que el Ministerio de Justicia no deniega esta segunda solicitud por estar ante una resolución provisional, sino porque en él se indica que las pruebas obtenidas son insuficientes para demostrar la implicación del (segundo) recurrente en los hechos delictivos, el Tribunal concluye que no puede exigírsele a él que acredite su inocencia y que no corresponde a la jurisdicción contencioso-administrativa determinar una eventual declaración de culpabilidad a la que no ha llegado al juez penal, falto de pruebas ( $§ 46)$. Se ha lesionado así su derecho a la presunción de inocencia ( $§ 47)$. Este razonamiento se ha utilizado para ambos recurrentes y ha sido confirmado en sede judicial, por lo que se confirma la lesión del derecho en ambos casos ( $\$ 48)$.

A la vista de estas resoluciones resulta aconsejable revisar la doctrina jurisprudencial relacionada con el artículo 294 LOPJ (recogida, entre otras muchas, en la STS de 21 de julio de 2015, que resuelve el recurso de casación 1273/2013 ${ }^{98}$ ).

La última condena es la recaída en el asunto Lizaso Azconobieta (2011), en la que el Gobernador Civil de Guipúzcoa anunció la detención del recurrente afirmando que era miembro de un comando de ETA responsable de tres atentados mortales cometidos en la $\operatorname{provincia}^{99}(\S 41)$.

El Tribunal recuerda que la protección del derecho a la presunción de inocencia es más extensa que la penal y exige que ningún representante del Estado o una autoridad pública declare que una persona es culpable de una infracción antes de que su culpabilidad haya sido establecida por un tribunal (\$ 37). Las autoridades pueden informar sobre los procedimientos en curso pero sin incurrir en apreciaciones o prejuicios sobre la culpabilidad de los afectados ( $\$ 39)$, siendo importante determinar el sentido real de las declaraciones, antes que su formulación literal. Dado que las declaraciones del responsable político fueron previas a que el detenido fuera presentado ante el juez (antes mismo de la apertura de acciones penales contra él) ( $\$ 42)$, y la vista de sus contenidos, resultan inconciliables con la presunción de inocencia $(\S 43)$.

En cuanto a las desestimaciones, en la mitad de los casos el Tribunal entiende que el alegato relacionado con la presunción es el mismo que el planteado sobre la falta de inmediación en la segunda instancia penal [asuntos Igual Coll (2009), Lacadena Calero (2011), Serrano Contreras (2012) y Vilanova Goterris y Llop García (2012)], y en Gómez de Liaño y Botella (2008) que no resulta preciso pronunciarse sobre el mismo apreciada la lesión del derecho a un tribunal imparcial.

En el asunto Vera Fernández-Huidobro (2010) el Tribunal considera que la condena impuesta al recurrente por parte del Tribunal Supremo se fundamenta en pruebas de cargo durante la instrucción y en el juicio oral (\$ 146) y que ha sido ampliamente motivada ( $\$ 147)$, por lo que desestima la queja. Y la queja se considera mal fundada (y por ello se inadmite) en los asuntos Alony Kate (2012) (§ 79) y Cano Moya (2016) (§ 54).

98 Id Cendoj 28079130062015100436.

99 Ver Gascón InCHAUSTI, F.: «Dimensión extraprocesal de la presunción de inocencia y derecho al honor». En Alcácer Guirao, R. Beladíez Rojo, M. y Sánchez Tomás, J.M. (coords.): Conflicto..., cit., pp. 351 ss. 


\section{III.4. La propiedad privada}

En nueve ocasiones el Tribunal de Estrasburgo ha debido pronunciarse, mediante Sentencia, sobre la eventual lesión del derecho a la propiedad privada (en 2 de ellas en conexión con el principio de no discriminación).

Especial trascendencia ha alcanzado el asunto Muñoz Díaz ${ }^{100}$ (2009), en el que el Tribunal de Estrasburgo censuró que se denegara la pensión de viudedad a la recurrente, que se casó mediante el rito gitano con su pareja. El Tribunal entiende que, habiéndosele facilitado un libro de familia, se la discrimina si no se le confiere dicha pensión. El Tribunal también entiende discriminatorio, en el asunto Manzanas Martín (2012), que el régimen de pensiones sea distinto y más perjudicial para los pastores evangélicos que para los padres católicos.

El asunto Muñoz Díaz guarda ciertas similitudes con el caso Aldeguer Tomás (2016) en el que se plantea la pretensión de que el recurrente cobre pensión de viudedad por la muerte de su compañero, con el que no ha podido casarse por no existir esta posibilidad hasta la reforma del código civil, producida en 2005. Apoya tal pretensión en la Ley que permite disfrutar de este beneficio a las parejas que no pudieron casarse porque uno de sus miembros, o ambos, tenía un vínculo matrimonial previo que no pudo romper por no estar prevista la figura del divorcio hasta 1981. El Tribunal acepta que la convivencia con una persona del mismo sexo forma parte de la vida privada y de la vida familiar (§ 75). Pero no comparte que la situación de esta pareja (que no ha podido casarse por no estar en aquél momento permitido) sea equiparable a la de las parejas heterosexuales que no pudieron hacerlo por no haberse regulado el divorcio ( $§ 87$ ). Por esta razón (que no se ve alterada por las posteriores reformas adoptadas por el Derecho español, § 89), y que se ve reafirmada por el margen de apreciación del que disponen los Estados en esta materia ( $\$ 90)$, concluye que el recurrente no ha sido discriminado por su orientación sexual. No deja de ser paradójico que el Tribunal ampare a una persona que, pudiendo haberse casado, opta por no hacerlo y no haga lo propio con quienes no tenían tal posibilidad.

Por otra parte, en el asunto Tendam ${ }^{101}$ (2010) se afirma que debe indemnizarse al recurrente por los bienes robados o dañados que habían sido secuestrados por la autoridad judicial. Nos queda por examinar el interesante asunto Sociedad Anónima del Ucieza ${ }^{102}$ (2014), en el que se cuestiona si la inscripción por parte de la Iglesia de una antigua iglesia cisterciense que se encuentra en el terreno (igualmente inscrito en el registro de la propiedad) de la sociedad recurrente vulnera su derecho a la propiedad privada. Señala el Tribunal que «el registro a nombre de la Diócesis de Palencia en 1994 implicó la pérdida

100 Ver, entre otros, Matia Portilla, F.J.:«Condena por una discriminación inexistente (Tribunal de Estrasburgo y matrimonio gitano)». REDC, 92, 2011, pp. 355 ss; Rey Martínez, Fernando: «La Sentencia del TEDH de 8 de diciembre de 2009: ¿un caso de igualdad en general o de discriminación étnica en particular?». La Ley, 7455, 2010; Martínez Rubio, A.: «El matrimonio gitano en España y sus efectos». En Goizueta Vértiz, J. y Cienfuegos Mateo, M. (dirs.): La eficacia de los derechos fundamentales de la UE. Cuestiones avanzadas. Thomson. Cizur Menor, 2014, pp. 573 ss. y, en relación con este asunto y Manzanas Martín, Gómez FernáNDEz, I.: «Abrir la puerta al reconocimiento de derechos sociales a través de la cláusula de igualdad». En AlCácer Guirao, R. BeLADíEz Rojo, M. y SÁNCHEZ Tomás, J.M. (coords.): Conflicto..., cit., pp. 641 ss.

101 Ver Martín Rebollo, L.: «Presunción de inocencia y responsabilidad del Estado: una relación paradójica». En García De Enterría, E. y Alonso García, R. (coords.): Administración..., cit. Vol. 2, pp. 2943 ss.

102 Ver Agudo Zamora, M.J.: «Privilegio inmatriculador de la Iglesia Católica y vulneración de principios constitucionales». Revista Crítica de Derecho Inmobiliario, 751, 2015, pp. 2631 ss. 
de los derechos que se derivaron para el solicitante del registro de 1979» (§90), «sin dar a este último la posibilidad de formular objeciones derivadas de la inscripción registral previa de la iglesia, que habrían hecho inaplicables los artículos 199 y 206 de la Ley hipotecaria» (\$ 92) (en los que se justificaba la actuación de la iglesia). Y es que «el artículo 206 de la Ley de Hipotecas no cumple suficientemente los requisitos de precisión y previsibilidad implícitos en el concepto de Ley del Convenio» ( $\$ 95)$. En efecto, su aplicación priva de todo efecto útil un derecho real inscrito en el registro de la propiedad y la nueva inscripción no podría producirse sin un debate contradictorio y respetando la igualdad de armas de las dos partes, lo que no ha ocurrido ( $\$ 96)$. A esto se suma que las jurisdicciones han interpretado la Ley permitiendo a la iglesia justificar su propiedad en razones históricas de carácter general (§ 97). También le sorprende al Tribunal que «un certificado elaborado por el secretario general del obispado puede tener el mismo valor que los certificados emitidos por funcionarios públicos investidos de prerrogativas de autoridad pública, y también se pregunta por qué el artículo 206 de la Ley Hipotecaria se refiere únicamente a los obispos diocesanos de la Iglesia católica, excluyendo representantes de otras confesiones» ( $(99)$ ). Subraya también que «no hay limitación en el tiempo para el registro así previsto y, por lo tanto, puede hacerse, como ha sido el caso aquí, de manera inoportuna, sin condición previa de publicidad e ignorando el principio de seguridad jurídica» ( $\$ 99)$. Y subraya, finalmente, que el recurrente no ha recibido una indemnización por lo acaecido.

El Tribunal concluye que «las circunstancias del caso, incluida la naturaleza excepcional de la medida en cuestión, junto con la falta de titularidad de la otra parte, la falta de debate contradictorio y la desigualdad de armas, combinado con la obstrucción al pleno disfrute del derecho a la propiedad y la ausencia de compensación, llevan al Tribunal a considerar que el solicitante tuvo que soportar una carga especial y exorbitante que rompió el equilibrio apropiado entre por un lado, los requisitos de interés general y, por otro, la salvaguardia del derecho al respeto de los bienes» ( $\$ 101)$. Pocos meses más tarde de esta Sentencia se aprueba la Ley 13/2015, de 24 de junio, de Reforma de la Ley Hipotecaria, que acaba con el muy anacrónico y discutible privilegio de la Iglesia Católica.

También presenta interés el asunto Aizpurua Ortiz y otros (2010), en el que los recurrentes se duelen de haber sido privados de sus derechos a una pensión complementaria sobre la base de un nuevo convenio colectivo concluido entre la sociedad y los representantes actuales de los trabajadores, sin haber contado con representación propia y haber podido defender sus intereses ( $§ 25)$. El Tribunal de Estrasburgo constata, sin embargo, que los recurrentes han podido defender sus posiciones en el proceso judicial ( $\$$ 52) y que el nuevo convenio colectivo no ha suprimido los derechos de los recurrentes, sino que han sido reemplazados por el pago de una única indemnización, y ha considerado igualmente la mala situación financiera de la sociedad (\$ 53). Así pues, la medida se inscribe en la defensa del interés general $(\$ 53)$ y no es discriminatoria (también han renunciado los trabajadores activos de la empresa a su futura pensión complementaria, $\S$ 54). El Tribunal de Estrasburgo rechaza el alegato referido a una directiva de la UE puesto que no es competente en tal campo ( $\$ 56)$, y entiende que el Estado español goza de margen de actuación para haber actuado así. El Juez Myjer discrepa de esta conclusión en su voto particular.

En el asunto Ruspoli Morenés (2011) se cuestiona si el Estado está obligado a pagar intereses legales si ejerce su derecho preferente de compra sobre obras de arte (en este caso 
la condesa de Chinchón, de Goya) y lo paga en sendas anualidades, como reclaman los vendedores. El Tribunal de Estrasburgo considera que el Estado dispone de un margen de apreciación muy extenso cuando regulan el uso de un bien ( $\$ 39)$, especialmente si ha sido declarado como de interés cultural o clasificado como patrimonio histórico ( $\$ 40)$. La Ley impone en estos casos el pago en dos anualidades (en realidad los dos ingresos se han realizado en año y medio) y no prevé ninguna actualización del precio (§ 45). El Tribunal concluye que los recurrentes no han sufrido una carga desproporcionada y excesiva (§ 46), por lo que desestima la queja.

No es inhabitual que el Tribunal entienda que con el alegato a la propiedad privada se está retomando una queja previamente examinada en el mismo asunto. En el asunto Gorraiz Lizarraga (2004) —con invocación también del derecho a la vida privada y al respeto del domicilio - el derecho al proceso debido por no poder participar ante el Tribunal Constitucional con ocasión de una cuestión de inconstitucionalidad y por una intervención del legislador autonómico y en el caso del asunto Aparicio Navarro Reverter y García San Miguel y Orueta (2017) el derecho de defensa, por no haber sido partes de un proceso en el que se acuerda demoler sus apartamentos. Finalmente, en el asunto Lacarcel Menéndez (2006) entiende el Tribunal de Estrasburgo que este alegato no precisa ser examinado separadamente de otro que ha sido previamente analizado y estimado.

\section{III.5. La intimidad y la vida privada (vertiente medioambiental)}

Agrupamos en este apartado las quejas relativas con el derecho a la intimidad y a la vida privada, en su vertiente medioambiental, aunque todas ellas se inscriben, en el marco del Convenio, en el artículo 8.1 del Convenio.

Comenzando por la intimidad, conviene subrayar que dos recientes Sentencias [asuntos Trabajo Rueda ${ }^{103}$ (2017) y López Ribalda y otros (2018)] hacen referencia a la intimidad en relación con la informática. En la primera de ellas se cuestiona, en síntesis, si la policía puede proceder, por su propia autoridad, a acceder al contenido de un ordenador portátil personal. El Tribunal Constitucional, con una construcción en cierta medida contradictoria, entendía que si bien el ordenador es un contenedor de intimidad personal y que para acceder a su contenido se precisa previa autorización judicial, existían circunstancias particulares en este caso que avalaban el comportamiento policial por razones de urgencia (STC 173/2011, de 7 de noviembre). Aunque el Tribunal considera que tal posibilidad puede considerarse prevista en la Ley (en sentido amplio) ( $\$ 38$ ) y perseguir fines legítimos (especialmente, en delitos sexuales y referidos a menores, § 39). Ahora bien, el problema es que «es difícil de apreciar» la urgencia invocada. No existe, pese a lo afirmado por nuestro Tribunal Constitucional, «ningún riesgo de desaparición

103 Ver Torres Benito, E: «El asunto Trabajo Rueda contra España ante el Tribunal Europeo de Derecho Humanos, o más bien Fiat justitia et pereat mundus». El Notario del siglo XXI 74 (2017), pp. 50 ss.; LARRÁYOZ SOLA, I.: «Vulneración del derecho al secreto de las comunicaciones en intervención de ordenador personal: STEDH, de 30 mayo (TEDH 2017, 45). Caso Trabajo Rueda contra España». Revista Aranzadi Doctrinal 2017/8, pp. 191 ss. y Heredero Campo, M.T.: «Sentencia del Tribunal Europeo de Derechos Humanos, Sección Tercera, de 30 de mayo de 2017. Caso Trabajo Rueda c. España (demanda n.. 32600/12)». Ars Iuris Salmanticensis, 2017/2, pp. 245 ss. 
de ficheros puesto que se trata de un ordenador secuestrado y retenido por la policía y no conectado a internet» ( $(46)$. La diligencia policial no resulta proporcionada al fin legítimo perseguido ni necesaria en una sociedad democrática $(\$ 47)$, por lo que se concluye en la lesión del derecho a la intimidad ( $\$ 48)$.

El asunto López Ribalda y otros ${ }^{104}$ (2018) tiene su origen en la decisión de un empresario de colocar cámaras visibles y ocultas, informando a los trabajadores de la existencia de las primeras, que controlan los accesos al negocio, y no sobre las segundas, que vigilan las cajas registradoras ( $§ 58)$. El Tribunal recuerda que la decisión del empresario trae causa del temor de que se estén produciendo robos ( $§ 62)$, que se produjeron grabaciones de los trabajadores que fueron visualizadas por diversas personas ( $\$ 63)$, sin que se les advirtiera a ellos ni de la existencia de ficheros de datos que les afectaban ni de que su área de trabajo estaba siendo grabada, como exige la legislación española (\$ 64). Los Tribunales entienden, pese a todo, que tal comportamiento está justificado y es necesario y proporcionado ( $\$ 66)$. No comparte este parecer el Tribunal de Estrasburgo, que recuerda que hay unas exigencias legales que deben respetarse ( $\$ 67)$, que la medida afectaba a todos los trabajadores y todos los turnos durante un largo periodo de tiempo, lo que hace que sea desproporcionada ( $\$ 69)$, por lo que considera vulnerado el derecho a la intimidad $(\S 70)$.

En el asunto C.C. $\left(2009^{105}\right)$ el Tribunal de Estrasburgo condena a España por no ocultar la identidad de una persona seropositiva que mantiene una disputa judicial con una compañía de seguros. Entiende que la divulgación de tal hecho puede tener consecuencias devastadoras en el plano familiar, social y profesional de la persona afectada $(\S$ 33) y, como no encuentra un motivo que justifique la publicación de este dato ( $\$ 40)$, concluye que se ha lesionado su derecho a la vida privada ( $\$ 41)$ (concebida, en este caso, como intimidad).

Finalmente, en el asunto Rubio Dosamantes ${ }^{106}$ (2017), se cuestiona si determinados comentarios sobre una persona famosa (sus presuntas tendencias homosexuales o bisexuales; su interrupción de un embarazo por motivos profesionales; su eventual influencia en que su novio en aquél momento se introdujera en el mundo de las drogas o en que le hubiera infringido malos tratos y humillaciones) realizados en varios programas del corazón pueden comprometer su intimidad y su honor. El Tribunal examina la cuestión desde la intimidad, recordando que si la notoriedad de la recurrente condiciona su vida

104 Ver García SALAS, A.I.: «El deber empresarial de informar acerca de la videovigilancia ejercida sobre los trabajadores». Revista de Información Laboral, 2, 2018, pp. 117 ss.; PreCiado DomÈnECH, C.H. «Comentario de urgencia a la STEDH de 9 de enero de 2018». En Revista de Información Laboral 1 (2018), pp. 41 ss., Rojo Torrecilla, E.: «Derecho del trabajador a la privacidad en la empresa y límites a su control por cámaras de vigilancia». Derecho de las Relaciones Laborales, 2, 2018, pp. 135 ss. y PÉrez CANET, A.: «De nuevo, sobre la videovigilancia como medida de control de la actividad laboral». Revista de Información Laboral 1 (2018), pp. 55 ss. Es preciso aludir, también, a la STEDH Gran Sala recaída en el asunto Barbulescu c. Rumanía (Sentencia de 5 de septiembre de 2017, demanda 61496/08), que ha generado un alto interés doctrinal. Ver Molina Navarrete, C.: «De Barbulescu II a López Ribalda: ¿Qué hay de nuevo en la protección de datos de los trabajadores?». Estudios Financieros. Revista de Trabajo y de Seguridad Social, 419, 2018, pp. 125 ss.

105 Ver López Ortega, J.J.: «A propósito de la protección de la confidencialidad de las informaciones médicas en la doctrina del Tribunal Constitucional». En Alcácer Guirao, R. Beladíez Rojo, M. y Sánchez Tomás, J.M. (coords.): Conflicto..., cit., pp. 501 ss.

106 Ver Mateo SANZ, J.B: «La esperanza legítima de protección y de respeto de la vida privada de las personas con proyección pública». En Cuadernos Civitas de Jurisprudencia Civil, 105, 2017, pp. 235 ss. 
privada, su protección es más larga que si mantuviera ocupaciones públicas (\$ 34). En esos programas los periodistas «se hacían eco con tono irónico y burlesco», recuerda el Tribunal que adujo la demandante, «de rumores sobre su presunta homosexualidad o bisexualidad». También sobre «una interrupción voluntaria de su embarazo por motivos profesionales», «el papel que habría jugado en el consumo de drogas por parte de su pareja en aquel momento» y «los malos tratos y humillaciones a los que ella le habría sometido». El Tribunal señala que no se trata de que sea deshonroso que se habla de una presunta homosexualidad, como señaló la jurisdicción española, sino de que este aspecto forma parte de la intimidad de una persona, sin que pueda ser revelada sin su consentimiento ( $(43)$. Lo mismo ocurre con el tipo de relación — tormentosa o no- que tuviera con su novio. Las jurisdicciones nacionales no han ponderado si la restricción impuesta sobre la intimidad de la recurrente era necesaria ( $\$ 46)$, por lo que considera que se ha vulnerado este derecho ( $\$ 48)$.

En los asuntos P.V. (2010), Fernández Martínez (2012) y De la Flor Cabrera (2014) se desestima la queja relacionada con el derecho a la intimidad. En el primer caso, en el que se invoca este derecho en combinación con el artículo 14, el Tribunal de Estrasburgo comparte el razonamiento realizado por los tribunales españoles ( $\$ 36)$, entendiendo que la decisión de modificar el régimen de visitas al hijo del recurrente no trae causa de que sea transexual, sino de su inestabilidad emocional, y que tal medida pretende proteger el interés superior del menor.

El asunto Fernández Martínez ${ }^{107}$ (2012) tiene su origen en la decisión del obispado de negar la venia docendi al recurrente, lo que le impide seguir siendo profesor de religión. El Tribunal maneja una noción amplia de vida privada, que incluye la social ( $\$ 56)$ y alcanza a las relaciones profesionales ( $\$ 57)$. Se recuerda también que las comunidades religiosas son titulares de los derechos reconocidos en los artículos 9 y 11 y que gozan de autonomía ( $(80)$, aunque deban respetar, en su actuación los derechos fundamentales (de acuerdo con la doctrina del Tribunal Constitucional). Pues bien, dado que la decisión eclesiástica trae causa de unas declaraciones del recurrente críticas con la Iglesia y que atañen a cuestiones diversas (celibato, aborto, divorcio, sexualidad, control de la natalidad...) (§ 84) estamos, a juicio del Tribunal de Estrasburgo, ante una motivación estrictamente religiosa, por lo que resulta justificada la actuación de la Iglesia. Además existe en esta relación un específico especial deber de lealtad por parte de los profesores de religión ( $\$ 85)$. Se concluye así que las jurisdicciones competentes han realizado un justo equilibrio entre diversos intereses privados», por lo que no se ha producido lesión del artículo $8 \mathrm{CEDH}$ (§ 89). Discrepa de esta posición el Magistrado Saíz Arnaiz, por entender que sí se ha vulnerado la vida privada del recurrente, pudiendo añadirse que esta Sentencia es contraria a la doctrina fijada por el Pleno del Tribunal Constitucional en la STC 38/2007 (que la Sala Segunda desconoce en la $128 / 2007$, referida al recurrente $\left.{ }^{108}\right)$.

107 Ver GIL Y GIL, J.L.: «La no renovación del contrato de trabajo de un sacerdote secularizado y casado, profesor de religión y moral católica». Anuario de Derecho Eclesiástico del Estado, 30, 2014, pp. 227 ss. y VALERo ESTARELLA, M.J.: «Autonomía institucional de las confesiones religiosas y derecho al respeto de la vida privada y familiar en Estrasburgo». Revista General de Derecho Canónico y Derecho Eclesiástico del Estado, 36, 2014.

108 Ver Matia Portilla, F.J.:«De declaraciones de idoneidad eclesiástica, obispos, profesores de religión y derechos fundamentales». Corts, 19, 2008, pp. 67 ss. 
Finalmente, el Tribunal de Estrasburgo entiende en el asunto De la Flor Cabrera $^{109}$ (2014) que la grabación del recurrente conduciendo en una moto con la que se pretende descartar que sufra una neurosis post traumática que le provoca un miedo intenso para conducir vehículos, como sostiene en un proceso judicial contra una compañía de seguros, no vulnera ni su intimidad ni su propia imagen. Ha sido realizada por una agencia de detectives que respeta las exigencias legales ( $\$ 39)$, se ha utilizado en un ámbito concreto y no público $(\$ 41)$ y con una finalidad prevista por el Derecho $(\$ 40)$.

Con el examen de este último asunto terminamos con las quejas referidas con el derecho a la intimidad personal y familiar. Y nos ocupamos de inmediato de las referidas a la contaminación medioambiental, que supone que los poderes públicos deben impedir que suframos en nuestro domicilio contaminación medioambiental (ruido, olores, humos...) que afecte al libre desarrollo de la personalidad. Este derecho guarda mayor relación con la vida privada que con la intimidad a la que se ha aludido con los casos anteriores.

Pues bien, la primera y más conocida resolución sobre esta línea jurisprudencial es la recaída en el asunto López Ostra ${ }^{110}$ (1994). En esta Sentencia se concluye que ni el Ayuntamiento de Lorca ni otros órganos del Estado (Ministerio Fiscal) (§ 56) «han sabido mantener un justo equilibrio» entre los intereses económicos locales (que se concretan en mantener la depuradora) y el disfrute del derecho al respeto de su domicilio y de su vida privada y familiar ( $\$ 58)$ y que el deber del Estado es hacer cesar la lesión en la vida privada de los recurrentes en su vivienda. Otros asuntos posteriores confirman esta doctrina en relación con ruidosos locales valencianos [asuntos Moreno Gómez $^{111}$ (2014) y Cuenca Zarnoso ${ }^{112}$ (2018)]. Esta última condena era previsible, dado que, aunque el Tribunal Constitucional había decidido acoger la doctrina del Tribunal Europeo de Derechos Humanos en esta materia, entendiendo que tal injerencia no impedida por las autoridades públicas lesiona, simultáneamente, los derechos a la intimidad y a la inviolabilidad del domicilio (STC 119/2001), deniega el amparo solicitado por Cuenca Zarnoso porque no existen mediciones fiables del nivel de ruido dentro de su vivienda. El problema es que desconoce la razonable afirmación que el Tribunal de Estrasburgo realizara en el asunto Moreno Gómez, de que no resulta preciso demostrar el alto nivel de ruido en una vivienda situada en una Zona Acústicamente Saturada, como era el caso (\$ 49).

109 Ver Pascual Medrano, A.: «Due process y derecho fundamental a la propia imagen». Revista Aranzadi Doctrinal, 6, 2014, pp. 129 ss.

110 Ver Lozano Cutanda, B.:«La ecologización de los derechos fundamentales: la doctrina López Ostra c. España, Guerra y otros c. Italia y Hatton y otros c. Reino Unido del TEDH y su recepción por nuestro TC». REDE, 2002/1, pp. 175 ss. y CASINO RuBIO, M.: «La contaminación ambiental y el derecho a la vida privada y familiar». En Alcácer Guirao, R. Beladíez Rojo, M. y Sánchez Tomás, J.M. (coords.): Conflicto..., cit., pp. 419 ss.

111 Ver Vives Antón, Tomás Salvador: «Comentarios a propósito de la STEDH de 16 de noviembre de 2004». En Quintero Olivares, G. Morales Prats, F. (coords.): Estudios de Derecho ambiental. Tirant Lo Blanch. Valencia, 2008, pp. 411 ss. y GómEZ RiEnO Y CARNOTA, E.: «El ruido, derechos fundamentales y medio ambiente». García De Enterría, E. y Alonso García, R. (coords.): Administración..., cit. Vol. 2, pp. 2915 ss.

112 Ver, sobre la STC 49/1999, Matia Portilla, F.J.: «Legislador, derechos fundamentales y proceso». REDC 58 (2000), pp. 245 ss., y sobre la resolución del Tribunal de Estrasburgo, MARTínez PÉREZ, E.J: «Sentencia del TEDH de 16 de enero de 2018, demanda núm. 23383/12, Cuenca Zarnoso c. España». Actualidad Jurídica Ambiental, 78, 2018, pp. 114 ss. 
Y lo mismo ocurre en el asunto Martínez Martínez ${ }^{113}$ (2011), en el que recuerda el derecho de la persona a disfrutar, con tranquilidad, del domicilio, protegiéndolo de ataques inmateriales como son los provocados por los ruidos, las emisiones, los olores y otras injerencias (\$ 39). Dado que el recurrente ha sufrido intensos niveles de ruido en su vivienda ( $\$ 48)$, y que esto haya tenido secuelas en la salud propia, en la de su mujer y en la de su hija (§ 49), sin que ninguna autoridad (ni la municipal, ni la autonómica, ni la judicial) haya puesto fin a esta injerencia ( $\$ 51)$, considera vulnerado el derecho a la vida privada $(\S 53)$.

No ocurre lo mismo en el caso Martínez Martínez y Pino Manzano (2012), en el que los recurrentes se quejan de una cantera cercana. El Tribunal desestima el motivo porque no ha quedado acreditado que la lesión medioambiental fuera significativa (ni en la intensidad del ruido ni en los niveles de polvo en suspensión, § 46). Además, los recurrentes se han instalado en una zona no residencial (primero rústica, luego industrial), por lo que se han situado voluntariamente en una situación irregular ( $\$ 48)$.

En el asunto Martínez Martinez (2011), examinado en este mismo epígrafe, se inadmite la queja de que a la ruidosa discoteca se le había conferido un régimen de ruidos más permisivo que a otros locales, que se vincula con los artículos 14 y 8 , por no apreciarse apariencia de violación.

Finalmente, en el asunto Ortuño Ortuño (2011) se invoca la vida privada con una motivación discutible, cuando se afirma que las dificultades existentes para poder educar a sus hijos vulnera este derecho, argumento que el Tribunal de Estrasburgo considera inconsistente ( $\$ 67)$.

\section{III.6. (re)Unión familiar}

Aludimos con esta denominación al derecho a que el Estado haga todo lo posible para evitar que se produzca la separación entre los padres y sus hijos. La primera condena en esta materia es la recaída en el asunto Iglesias Gil y A.U.I. ${ }^{114}$ (2003), en la que se afirma «que las autoridades españolas no desplegaron los esfuerzos adecuados y suficientes para hacer respetar el derecho de la demandante al regreso de su hijo y el derecho de este último a reunirse con su madre» ( $(62)$, aunque no se pueda reprochar al juez penal interno una total inactividad, como pretende la demandante $(\$ 60)$. Esta resolución contrasta con la dictada en el asunto Tapia Gasca y D. (2009), en la que se desestima la queja porque, en este caso, las autoridades nacionales han adoptado numerosas actuaciones tendentes a asegurar la pronta devolución del menor.

En el asunto Saleck Bardi ${ }^{15}$ (2011) el Tribunal estima que en el debate procesal sobre el futuro de la hija de la recurrente ha sido correcto (no se vislumbra que el órgano judicial haya vulnerado el principio de imparcialidad, ni admite reproche la denegación

113 Ver Monestier Morales, J.L.: «Asunto Martínez Martínez contra el Reino de España». Práctica Derecho Daños 118 (2014), pp. 8 ss. y García Ureta, A.M.: «El ruido ante el Tribunal Europeo de Derechos Humanos». Actualidad Jurídica Ambiental, 2011/7, pp. 15 ss.

114 Ver Cuartero Rubio, M.V.: «Sustracción internacional de menores y derecho al respeto de la vida familiar». En Alcácer Guirao, R. Beladíez Rojo, M. y Sánchez Tomás, J.m. (coords.): Conflicto..., cit., pp. 471 ss.

115 Ver González Beilfuss, M.: «La dimensión objetiva del derecho a la vida familiar». En AlCácer GuIrao, R. Beladíez Rojo, M. y Sánchez Tomás, J.M. (coords.): Conflicto..., cit., pp. 537 ss. y Acuña San Martín, 
de algunas pruebas, ni la decisión adoptada al amparo de un abundante material probatorio) ( $\$ 56)$, pero aprecia una «falta de diligencia en el procedimiento desarrollado por las autoridades responsables de la duración de la residencia de la menor en España» ( $\$$ 58). Y es que «Saltana ha permanecido de facto con la familia de acogida después de la expiración de su estancia de dos meses en España», y dos años más tarde se ha decretado su situación de abandono. Se ha producido, pues, «una inactividad total de las autoridades administrativas de septiembre de 2002 a mayo de 2004 y observa [el Tribunal] que ninguna explicación satisfactoria ha sido dada para justificar este plazo de cerca de dos años para que la administración decida tutelar a la menor que no tenía entonces ningún título legal de residencia en España» (§ 61). Y ninguna sanción se ha impuesto a la familia de acogida a pesar de su actitud obstruccionista y su reiterada negativa a entregar a la menor a los servicios competentes para facilitar su retorno con su madre biológica» ( $\S$ 61), pese a carecer de cualquier título jurídico para tutelarla. Hay que esperar al 30 de abril de 2007 para que una nueva resolución judicial confiera la tutela de la menor a la familia de acogida, subrayando la inacción de la Administración (§ 63). Ha faltado, pues, «la obligación de celeridad particularmente exigible en este tipo de asuntos» ( $\$ 65)$.

Esta última carencia se aprecia igualmente en el asunto K.A.B. (2012), en la que el padre biológico de un menor, cuya madre había sido previamente expulsada, trata de impedir que sea trasladada a un concreto centro de acogida. Se cuestiona la urgente expulsión de la madre ( $\$ 108)$, o que no se le informara al recurrente de que podía solicitar el beneficio de justicia gratuita (lo que le podía haber permitido realizar el test de paternidad que estableciera la filiación, y que no pudo realizar por falta de medios, $\S \S$ 110-111). El Tribunal de Estrasburgo concluye que «el paso del tiempo, consecuencia de la inercia de la administración, la expulsión de C. sin que se hubieran tomado precauciones necesarias, la falta de apoyo y de asistencia al recurrente en un primer momento cuando su situación social y financiera era más frágil, así como la ausencia de ponderación de las decisiones dictadas por las jurisdicciones internas en cuanto a la imputación de responsabilidades en la situación de abandono del menor y la conclusión de falta de interés del recurrente por su hijo, han contribuido de forma decisiva a la ausencia de toda posibilidad de reagrupación familiar entre el recurrente y su hijo» (\$ 114).

Queda por examinar el asunto R.M.S. (2013), en el que se ampara a una madre que fue separada de su hija a pesar de haber impugnado en sede judicial tanto la declaración de situación de abandono de la menor como el acuerdo administrativo de situar a su hija en situación de acogida preadoptiva. Estamos en un supuesto peculiar, en el que tanto una asistente social como un órgano judicial afirman que la madre no muestra ningún interés por el estado de la menor cuando ha quedado acreditado que ha acudido 17 veces al centro de acogida en el que pensaba que se encontraba. Por otra parte, se cuestiona también que la declaración de la situación de abandono de la menor traiga causa, exclusivamente, de la carencia de medios materiales ( $§ 84)$, siendo más procedente la adopción de otras medidas sociales (vivienda social, ayudas, etc.). Además, los jueces han ignorado el hecho de que la situación económica de la recurrente mejorara posteriormente, y la adopción se justifica en la falta de contactos entre madre e hija cuando es la Administración quién los ha impedido... «Así, el tiempo transcurrido, consecuencia de la inercia de la administración y la

M.: «Un caso de violación del art. $8^{\circ}$ del Convenio Europeo para la Protección de los Derechos Humanos y de las Libertades Fundamentales por pasividad de la Administración». Estudios Constitucionales, 2012/2, pp. 685 ss. 
propia inercia de las jurisdicciones internas, que no han estimado irrazonables los motivos aportados por la administración para privar a una madre de su hija sobre la única base de motivos económicos - la salud mental de la recurrente, inicialmente invocada, no ha sido objeto de ninguna pericial — han contribuido de forma decisiva a la ausencia de toda posibilidad de reagrupación familiar entre la recurrente y su hija» (§ 92). Se evidencia, pues, que el Estado no ha respetado el artículo 8.

Aunque no hay más Sentencias sobre esta materia, debemos citar también el asunto G.V.A. (2015), en el que se ha producido un acuerdo entre España y la víctima, que nos ha evitado una segura condena. En el caso en especie, se había expulsado a la madre de una menor cuyo padre estaba en la cárcel, contraviniendo la doctrina del Tribunal Europeo de Derechos Humanos en la materia.

\section{III.7. Los restantes derechos materiales}

Vamos a hacer una breve referencia a los restantes derechos materiales, en las que se han producido 10 condenas (de las 36 alegaciones examinadas).

Se han producido 3 condenas en relación con el derecho a que no se produzcan detenciones ilegales (artículo 5.1), en los asuntos Riera Blume y otros ${ }^{116}$ (1999), Dacosta Silva ${ }^{117}$ (2006) y Del Río Prada (2012). En el primer asunto por la retención a la que fueron sometidos los miembros de una asociación (presunta secta) en contra de su voluntad. En el segundo asunto por el arresto domiciliario y no judicial de un Guardia Civil por un superior, cuando este cuerpo ya no forma parte de las fuerzas armadas, que ha llevado a suprimir esta modalidad de sanción en 2007. En el tercero porque, determinado que el nuevo cómputo del tiempo de condena vulnera el principio de legalidad penal, cada día de prisión adicional resulta, lógicamente, ilegal.

En cuanto a los asuntos en los que esta queja se desestima debemos comenzar por Drozd y Janousek (1992), en el que el Tribunal concluye que no puede imputarse a España y Francia resoluciones judiciales adoptadas en Andorra (excepciones ratione loci y ratione personae), aunque diversos Magistrados (Petttiti, Valticos y Lopes Rocha, a la que se suman sus colegas Walsh y Spielmann) discrepan de tal parecer. En el asunto Scott (1996) se avala, con el voto discrepante de Repik, la detención del recurrente sobre el que pesa una solicitud de extradición. Y también se considera legal la privación de libertad sufrida por Raf (2003)

En Tendam (2010) el Tribunal de Estrasburgo no aprecia tampoco lesión alguna porque el recurrente haya sufrido prisión provisional y considera este motivo (que

116 Ver Pulido Quecedo, M.: «Sectas, delito de detención ilegal y jurisdicción constitucional». Repertorio Aranzadi del Tribunal Constitucional 1999/3, pp. 2481 ss.; Monge Fernández, A.: «Derecho a la libertad y a la seguridad. Comentario a la Sentencia del Tribunal Europeo de Derechos Humanos de 14 de octubre de 1999». Actualidad Penal 2001/25, p. 557; Motilla, A.: «Desprogramación y libertad religiosa». Quaderni di Diritto e Politica Ecclesiastica 2002/3, pp. 817 ss. y Flores Giménez, F.: «Sectas, libertad religiosa y detención ilegal». En AlCÁCer Guirao, R.; Beladíez Rojo, M. y Sánchez Tomás, J.M. (coords.): Conflicto..., cit., pp. 63 ss.

117 Ver, entre otros, Pérez Sola, N.: «El régimen disciplinario de la Guardia Civil y su compatibilidad con el Convenio Europeo de Derechos Humanos». RDP, 71-72, 2008, pp. 675 ss.; Manero Salvador, A. «El alcance restrictivo de las reservas al CEDH». REDI 2007/1, pp. 386 ss.; y DíAz PÉrez DE MADrid, A.: «STEDH de 02.11.2006, Dacosta Silva c. España, 69966/01». Revista de Derecho Comunitario Europeo 2008/30, pp. 527 ss. y Ripoll Carulla, S.: «Arresto domiciliario y derecho a la libertad». En Alcácer GuiraO, R. Beladíez Rojo, M. y SÁnCHEZ Tomás, J.M. (coords.): Conflicto..., cit., pp. 113 ss. 
también alude al artículo 3) mal fundado. Finalmente, en A.C. y otros (2014), el Tribunal considera que la queja referida a este derecho y a los derechos a la vida y a la interdicción de torturas y malos tratos (artículos 2 y 3) son prematuras, dado que no se ha producido el traslado de los demandantes de asilo, a Marruecos (en donde, a su decir, peligran estos derechos).

Así, pues, Temdam (2010) y A.C. y otros (2010) son dos de los asuntos en los que se desestima la lesión del derecho a la interdicción de tortura y malos tratos. También se hace en todos los asuntos de detenidos (casi siempre en relación con terrorismo) que denuncian haber sufrido malos tratos o torturas Lasuntos Martínez Sala y otros $(2004)^{118}$, San Argimiro Isasa (2010), Beristain Ukar (2011), Etxebarría Caballero (2014), Ataun Rojo (2014) y Beortegui Martínez (2016)], hasta el asunto Portu Juanenea y Sarasola Yarzaba (2018), en el que, a la vista de las lesiones sufridas por uno de los recurrentes, se condena a España por haber infringido malos tratos ${ }^{119}$. Previamente, en el asunto B.S. (2012) se había también establecido que no había quedado acreditado (ni había sido debidamente investigado) si la policía había infringido malos tratos o no a una prostituta nigeriana.

Las restantes desestimaciones en relación con este derecho se producen en los asuntos López Ostra (1994) (las molestias sufridas por la contaminación medioambiental no constituyen un trato degradante, $\S 60$ ), Olaechea Cahuas (2006) (no hay elementos suficientes que permitan concluir que la extradición del recurrente a Perú haya provocado la lesión de este derecho, debiendo examinarse el eventual incumplimiento por parte de España de la medida cautelar decretada por el Tribunal de Estrasburgo, § 44), Murillo Espinosa (2007) (queja referida a la denegación de pruebas solicitadas y que debe ser inadmitida por no haber sido incluida en la demanda, § 40), y López Elorza (2017) (en el que se indica que el riesgo de que el demandante pueda ser condenado a cadena perpetua en Estados Unidos es tan pequeño e hipotético que no se aprecia riesgo de lesión, § 119). En todo caso, se suspende la medida hasta que la Sentencia sea firme (hecho ya acaecido).

Cuatro motivos recogidos en las Sentencias del Tribunal Europeo de Derechos Humanos aluden al derecho al secreto de las comunicaciones. En la relevante Sentencia Valenzuela Contreras ${ }^{120}$ (1998) el Tribunal entiende que la calidad de la normativa española que regula las interceptaciones de las comunicaciones lesiona el artículo 8. Si posteriormente cambia de opinión, es porque integra en el Derecho la relevante doctrina jurisprudencial del Tribunal Constitucional y del Tribunal Supremo en la materia, aunque se produzca otra condena en Prado Bugallo ${ }^{121}$ (2003), por aludir a hechos previos a

118 Ver Queralt Jiménez, A.: «La vertiente procedimental del derecho a no sufrir torturas ni penas o tratos inhumanos o degradantes». En Alcácer Guirao, R.; Beladíez Rojo, M. y Sánchez Tomás, J.M. (coords.): Conflicto..., cit., pp. 37 ss. y Ruiloba Alvariño, J.: «La Sentencia del TEDH en el asunto Martínez Sala y otros c. España». REDI, 2005/1, pp. 209 ss.

119 Un análisis más detallado, supra, en el epígrafe 2.5.

120 Ver Rodríguez Ruiz, B.: «El caso Valenzuela Contreras y nuestro sistema de derechos fundamentales». REDC 56 (1999), pp. 223 ss. y SÁNCHEZ YlLERA, I.: «La deficiente calidad de las normas que habilitan la intervención de las comunicaciones telefónicas». En Alcácer Guirao, R.; Beladíez Rojo, M. y Sánchez Tomás, J.M. (coords.): Conflicto..., cit., pp. 443 ss.

121 Ver GARCía LÓPEZ, E. «Las intervenciones telefónicas, una crisis anunciada: comentario a la STEDH de 18 de febrero de 2003, caso Prado Bugallo c. España». Actualidad jurídica Aranzadi 594 (2003), pp. 1 ss.; YLLANES SuÁrez, J.P.: «Comentarios a la sentencia del Tribunal Europeo de Derechos Humanos de 18 de febrero de 2003 
la misma. Por este mismo motivo se desestima el motivo en el asunto Alony Kate (2012) $\mathrm{y}$, finalmente, en el asunto Marcos Barrios (2010) se inadmite el motivo porque las grabaciones no fueran utilizadas en el proceso ( $\$ 52)$.

Solamente hemos sido condenados una vez porque una privación de libertad haya sido excesiva en su duración. Es la sufrida por Scott (1996) ${ }^{122}$, que duró más de 4 años, para su extradición. La queja no prospera en Raf (2003) porque en este caso una buena parte de la privación de libertad se anuda a una condena penal impuesta en nuestro país (§ 64). En Van der Tang ${ }^{123}$ (1995) el Tribunal entiende que la prisión provisional del encausado era razonable por el alto riesgo de fuga que concurría en la causa ( $\$ 76)$. Y, finalmente, en Sanz Casla (2013) se hace una vaga invocación del artículo 5 en el que se indica que la pena de prisión debería haber sido suspendida, motivo que es inadmitido por falta de agotamiento ( $\$ 41)$, al no haberse incluido esta queja en la demanda de amparo.

El Tribunal ha amparado en una única ocasión el derecho a ser informado de la acusación (artículo 6.3.a) en el caso Varela Geis (2013), en relación con los derechos a disponer de tiempo para la defensa y el mismo derecho de defensa (artículos 6.3.b y 6.1), a la persona que fue acusada de negacionismo y condenada, en apelación, por un delito de justificación del holocausto. No se ampara este derecho en los casos Gea Catalán (1995) (por la claridad de la calificación jurídica realizadas por el Juzgado de Instrucción, sin que pueda derivarse la lesión de un mero error material en las conclusiones del Ministerio Fiscal, $\S \S 29$ y 28), Salvador Torres (1996) (dado que el desempeño de funciones públicas era un elemento intrínseco de la acusación de la desviación de fondos públicos, por lo que no resulta sorprendente la imposición de una agravante vinculada a este dato, § 33) y Pérez Martínez (2016) (dado que el Tribunal Supremo abrió un plazo de alegaciones para determinar si la comisión delictiva podría haberse producido por omisión, $\S$ 27). En este último caso se inadmite la queja conjunta de la falta de tiempo para preparar la defensa.

De esta forma, hemos realizado un detenido examen de todos los derechos que hemos definido como procesales y materiales, pero aún debemos examinar otras disposiciones del Convenio. Lo haremos, brevemente, a continuación.

\section{OTRAS DISPOSICIONES DEL CONVENIO}

En Este último epígrafe nos detendremos en tres preceptos del Convenio Europeo de Derechos Humanos que también han sido tratados en las Sentencias del Tribunal de

\footnotetext{
(Asunto Prado Bugallo c. España)». Repertorio Aranzadi del Tribunal Constitucional 2003/1, pp. 1949 ss.; CACHO SÁNCHEZ, Y.: «Las intervenciones telefónicas y el artículo 8 del Convenio Europeo de Derechos Humanos: sentencia del TEDH, Prado Bugallo c. España, de 18 de febrero de 2003». Revista General de Derecho Europeo 2003/1 y Català I Bas, A.: «Sentencia del Tribunal Europeo de Derechos Humanos Prados Bugallo c. España de 18 de febrero de 2003». REDF, 2003/1, pp. 127 ss.

122 Ver QuAdra-Salcedo Janini, T.: «El derecho del sujeto en prisión provisional a ser juzgado en un plazo razonable o a ser puesto en libertad durante el procedimiento». En AlCÁcer Guirao, R.; BeladíEz Rojo, M. y SÁNCHez Tomás, J.M. (coords.): Conflicto..., cit., pp. 87 ss.

123 Picatoste Bobillo, J.: «El caso Van der Tang contra España: el plazo razonable de prisión preventiva». Revista Xurídica Galega, 12, 1996, pp. 13 ss.
} 
Estrasburgo referidas a España y que no tienen un fácil encaje en los apartados anteriores. Hacemos alusión a la cláusula antidiscriminatoria, al mismo derecho de presentar un recurso ante el Tribunal de Estrasburgo y la prohibición de expulsiones colectivas (artículos 14,34 y $\mathrm{P} 4.4)$.

Comenzando nuestro examen por el artículo 14, conviene recordar que éste precepto ha sido invocado en 17 ocasiones y amparado solamente en 3 de ellas.

Como es sabido, este precepto solamente puede ser invocado en combinación con otro precepto del Convenio Europeo de Derechos Humanos. Hemos examinado las quejas amparadas en los apartados correspondientes a esos derechos sustantivos. Al hablar de la propiedad privada hicimos expresa alusión a los asuntos Muñoz Díaz (2009), Manzanas Martín (2012) y Aldeguer Tomás (2016), y al hablar de la dimensión material de los tratos degradantes al caso B.S. (2012) (apartados 3.4 y 3.7, respectivamente). Hemos situado además los asuntos P.V. (2010) y Fernández Martínez (2012), en los que se desestima el alegato, en el epígrafe dedicado a la intimidad (apartado 3.5).

Quedaría, pues, hacer referencia a los restantes casos desestimados o inadmitidos, que son muchos. De entrada, el motivo no puede ser examinado si se invoca el artículo 14 de forma aislada ${ }^{124}$. En otros supuestos se rechaza el motivo porque no se aprecia la lesión aducida ${ }^{125}$. También es habitual que el Tribunal de Estrasburgo acuerde no examinar esta queja separadamente de otra ya resuelta ${ }^{126}$. Finalmente, en otros casos no se pueda examinar por falta de agotamiento [en el asunto Gutiérrez Suárez (2010) no fue invocada en amparo] o por estar mal fundada ${ }^{127}$.

En dos ocasiones, el Tribunal Europeo de Derechos Humanos ha condenado a España por perjudicar el derecho al recurso previsto en el artículo 34 del Convenio. Esto ocurre cuando no respeta las medidas cautelares (artículo 39) que ha adoptado previamente. Como ha señalado en el asunto Olaechea Cahuas (2006), «la simple inobservancia de una medida cautelar acordada por el Tribunal [de Estrasburgo] en función de la existencia de un riesgo es, en sí mismo considerada, una grave traba, en ese momento preciso, al ejercicio efectivo del derecho de recurso individual» ( $\$ 81)$. Se cuestiona, en este caso, la extradición realizada a un presunto miembro de la red peruana del Sendero Luminoso, que desconoció la medida cautelar previamente adoptada desde Estrasburgo. Desde esta perspectiva, conviene insistir ahora en la imperiosa necesidad de conferir a los recursos judiciales que impugnan resoluciones administrativas que deniegan al asilo interesado un efecto suspensivo sobre la expulsión de los afectados [asunto N.D. y N.T. (2017)]. Aunque este dato ya ha sido subrayado al examinar las lesiones del derecho a un recurso efectivo, nos parece tan relevante en el marco del presente estudio que debemos reiterarlo aquí, porque tal modificación evitaría la creciente demanda de medidas cautelares que en esta materia se plantean ante el Tribunal de Estrasburgo.

También se vulnera el artículo 34 cuando el Estado se niega a facilitar al afectado, que se encuentra en una situación de particular vulnerabilidad y dependencia, como es

124 Asuntos Gómez de Liaño y Botella (2008) y Fernández Martínez (2012).

125 Asuntos Gómez de Liaño y Botella (2008), en combinación con el artículo 6.1; Polanco Torres y Movilla Polanco (2010), en combinación con el artículo 8; y Vlieeland Boody y Marcelo Lanni (2016), en relación con el artículo 6.2.

126 Asuntos Fuentes Bobo (2000), Otegi Mondragón (2011), B.S. (2012), R.M.S. (2013), Sociedad Anónima del Ucieza (2014) y Fernández Martínez (2012).

127 Asuntos Martínez Martínez (2011) y Del Río Prada (2012). 
un preso, las copias de los documentos que precisan y que no puede obtener sin su respaldo $(\$ 50)$.

Finalmente, en la muy relevante Sentencia N.D. y N.T. ${ }^{128}$ (2017), que acabamos de citar, también se condena a España por realizar expulsiones colectivas (artículo P4.4), que son las realizadas a los irregulares que logran atravesar la valla de Melilla. Resulta evidente que, una vez que entran en suelo español, los extranjeros en situación irregular disponen de derechos humanos (como es solicitar asilo) y que su expulsión debe ajustarse a la legislación prevista a tal fin.

$* * *$

TITLE: Exam of the ECHR Judgments about Spanish Kingdom

ABSTRACT: The study is a joint exam of the more than a bundred ECHR Judgments condemnating the Spanish Kingdom. We make a global analysis comparing them within our nearest neighbours, while following a chronological path. Also we aim to make a statistical survey about the main rights claimed in Strasbourg, closely related to both substantive and procedural rights. We find necessary, also, to fit better the Strasbourg Case-Law terms into our national legal and fundamental rights terms. Finally, we give a basic synthesis on the main lines given in that Case-Law of every single right, maybe useful to set the light and shadow of our fundamental rights system.

RESUMEN: El presente estudio realiza una valoración conjunta del centenar y media de Sentencias del Tribunal de Estrasburgo en las que el Estado demandado es el Reino de España. Se realiza tanto un análisis global comparado en relación con países de nuestro entorno, como un examen cronológico de los asuntos que nos afectan. Se realiza también un estudio estadístico de los derechos más invocados y de las condenas reiteradas en relación con los derechos procesales y materiales. Resulta necesario, para acometer esta tarea, acomodar previamente la terminología empleada por el Tribunal Europeo de Derechos Humanos a nuestra dogmática de los derechos fundamentales. Se ofrece, finalmente, una síntesis básica de la doctrina jurisprudencial sobre cada uno de los derechos examinados, que es útil para determinar las luces y las sombras que la protección de los derechos presenta en nuestro país.

KEY WORDS: European Court of Human Rights, buman rights, constitutional rights.

Palabras clave: Tribunal Europeo de Derechos Humanos, derechos bumanos, derechos constitucionales.

FECHA DE RECEPCIÓN: 25.06.2018 FECHA DE ACEPTACIÓN: 13.09.2018

128 Ver VALDÉs DAL-RÉ, F.: «Las expulsiones colectivas de extranjeros: su tratamiento en el ordenamiento internacional y la jurisprudencia del Tribunal Europeo de Derechos Humanos». Derecho de las Relaciones Laborales 4 (2018), pp. 357 ss. y SÁNCHez Tomás, J.M.: «Las devoluciones en caliente en el TEDH». REDE, n. ${ }^{\circ}$ 65, 2018, pp. 101 ss. 